\title{
Contexto e Competição na Política Paulista*
}

\author{
Rachel Meneguello ${ }^{1}$
}

Fernando Bizzarro Neto ${ }^{2}$

${ }^{1}$ Professora do Departamento de Ciência Política da Universidade Estadual de Campinas (Unicamp), diretora do Centro de Estudos de Opinião Pública da mesma universidade e pesquisadora do Conselho Nacional Científico e Tecnológico (CNPq). E-mail: racael@unicamp.br.

${ }^{2}$ Mestrando em Ciência Política do Instituto de Filosofia e Ciências Humanas (IFCH) da Universidade Estadual de Campinas (Unicamp) e pesquisador vinculado ao Centro de Estudos em Opinião Pública (Cesop/Unicamp). E-mail: fbizzarroneto@gmail.com.

\section{INTRODUÇÃO}

— ste artigo analisa as transformações da política local e das bases Eleitorais dos partidos em São Paulo sob o cenário multipartidário do período pós-1985. São dois os argumentos desenvolvidos. O primeiro funda-se no enfoque da geografia eleitoral para identificar as bases locais e a movimentação eleitoral dos partidos no estado, a partir dos resultados oficiais por município das eleições locais e estaduais. Aqui, o objetivo é analisar sobretudo os possíveis efeitos das mudanças estruturais observadas nesse período de aproximadamente trinta anos, em específico nos municípios do interior, sobre a movimentação eleitoral e a competição partidária.

Sabemos que o comportamento político e o voto respondem a uma dinâmica ampla e combinada de fatores objetivos e subjetivos, e variam entre indivíduos inseridos em diferentes processos de socialização, e consideramos que fatores geográficos e estruturais estabelecem cenários que favorecem a constituição de orientações políticas específicas, e associam-se, em alguma medida, a formas locais de organização polí-

\footnotetext{
* Trabalho apresentado no 35ํㅡㄹ Encontro Anual da Associação Nacional de Pós-Graduação e Pesquisa em Ciências Sociais (Anpocs), Caxambu, MG, outubro de 2011. Agradecemos a Yan Carreirão, Bruno Speck e aos pareceristas da Dados pelos comentários aqui incorporados.
}

DADOS - Revista de Ciências Sociais, Rio de Janeiro, vol. 55, n-1, 2012, pp. 119 a 171. 
tica. Assim, a análise vai em busca de algumas explicações para as diferentes tendências de desenvolvimento eleitoral da política paulista à luz da combinação entre fatores estruturais socioeconômicos e o fator espacial, que sugere a importância da proximidade com polos de difusão política na definição do voto.

Desde o trabalho de Simão (1956) sobre o voto operário na periferia paulistana, passando pelos trabalhos sobre a dinâmica eleitoral durante o bipartidarismo e o apoio dos maiores municípios do estado ao MDB* (Faria, 1975; Lamounier, 1980; Meneguello e Alves, 1986; Kerbauy, 2000), o processo de urbanização e seu impacto sobre as práticas políticas definem uma clivagem fundamental para entender os padrões de apoio eleitoral aos partidos em São Paulo - assim como no país em geral, como apontam Reis e Castro (1992) e Avelar e Walter (2008). Segundo os vários autores, municípios maiores nos quais as práticas políticas tradicionais perderam espaço para práticas modernas implicadas pelo processo de urbanização apresentavam padrões diferenciados de votação, quando comparados aos municípios menores e de população menos urbanizada.

No decorrer da transição democrática, as eleições de 1982 não alteraram o quadro de preferências, marcado pela concentração do voto conservador nos menores municípios paulistas, nos quais a presença da Arena/PDS era dominante, assim como não alteraram a concentração do voto de oposição ao regime militar via MDB/PMDB nos maiores municípios. A reforma de partidos em 1979 levou o voto oposicionista a distribuir-se em outros canais além do PMDB, nos novos partidos PT, PDT e PTB, mas o contexto político marcado pela clivagem entre o urbano e o rural, entre municípios pouco e muito urbanizados, ainda marcaria o estado até os primeiros anos do período democrático (Meneguello, 1989; Gonçalves, 1998).

É, contudo, a partir das eleições de 1986 que os padrões de votação dos partidos em São Paulo passam a diferir das tendências encontradas nas eleições anteriores. Desde o processo de "interiorização" do PMDB (Sadek, 1989), a partir da vitória de Orestes Quércia na disputa para o governo do Estado, até o forte declínio eleitoral do partido no período 1990-2010, significativas transformações marcaram o sistema partidário paulista e suas bases eleitorais.

* Ver lista de siglas dos partidos políticos com os respectivos significados ao final do artigo. 
Essas transformações relacionam-se ao segundo argumento deste artigo, segundo o qual o sistema paulista organizou-se, a partir de 1994, por meio de dois vetores: a) o primeiro, a organização da política nacional, levando a que, já no início da década de 2000, os polos políticos resultassem da partilha de preferências entre PSDB e PT. Os dois partidos que lideram a política nacional no período pós-1994 têm em São Paulo parte significativa de suas bases eleitorais e organizativas, o que lhes dá condições para protagonizar também as principais disputas estaduais - especialmente após o enfraquecimento definitivo do malufismo - e exercer um efeito estruturador sobre a política, semelhante ao que tem ocorrido nas eleições nacionais; b) o segundo vetor, a estruturação das preferências pelos principais partidos organizados na década de 1980. Ainda que a dinâmica paulista se estabeleça sob um notável quadro de competitividade, com um amplo terreno político (um espaço para 6.270 vereadores, 645 prefeitos, 94 deputados estaduais e 70 deputados federais), e tenha possibilitado, já a partir de 1985, um rearranjo de elites com o surgimento de um expressivo número de médias e pequenas legendas que encontraram espaço para acomodação de interesses (Braga e Kinzo, 2007), são poucas as agremiações que estruturam o voto, e que constituem, ao longo do tempo, espaços de tendências e redutos resistentes à alta fragmentação que o estado possibilita.

Esse aumento da competitividade também ajuda a compreender a aguda trajetória declinante do PMDB, que teve suas expressivas bases locais herdadas do período bipartidário redirecionadas a múltiplos competidores, tanto devido às transformações das preferências, quanto à reacomodação das elites frente à ampliação do quadro de ofertas. $\mathrm{O}$ partido que predominou sobre a política paulista com as eleições de 1974, concentrou o voto oposicionista na pressão eleitoral pela abertura política, elegeu por três vezes o governador estadual (Franco Montoro em 1982, Orestes Quércia em 1986 e Luiz Antônio Fleury Filho em 1990) e a maioria dos senadores, deputados e prefeitos do Estado no período, terminou por enfrentar um significativo declínio desde os primeiros anos da década de 1990, que culminou nas eleições de 2010, quando o partido não lançou candidato para o governo estadual e a sua principal liderança, Quércia, abriu mão da candidatura ao Senado por motivos de doença que o levou à morte dois meses após as eleições. Dessa forma, a caracterização das bases eleitorais do PMDB nas décadas de 1990 e 2000, assim como a análise da ocupação dos seus espaços pelas demais agremiações, são elementos centrais para a compreensão dos vetores da competição político-partidária paulista. 
O artigo está dividido em três partes. Na primeira seção apresentamos o cenário partidário paulista entre 1986-2010, focalizando as características da competição estabelecida no período e a reacomodação de elites. Em seguida, na segunda seção, apresentamos os supostos da análise contextual e socioeconômica que orienta esse estudo eleitoral e analisamos os dados sob duas abordagens, a análise das votações segundo fatores socioeconômicos e segundo a sua distribuição regional. $\mathrm{Na}$ análise da distribuição regional do voto damos especial atenção ao PMDB, procurando mostrar aspectos de sua trajetória declinante. Finalmente, apresentamos considerações sobre os dados.

\section{O TERRENO POLÍTICO PAULISTA E A TRAJETÓRIA DO SISTEMA PARTIDÁRIO}

Este artigo está limitado à análise das votações para os cargos de prefeito, deputado estadual e governador entre 1990 e 2010. Acompanhamos a ideia de que os sistemas eleitorais majoritário e proporcional produzem parâmetros distintos de escolha para o eleitor (Lijphart, 1984; Dalton e Anderson, 2011). Assim, entendemos que os elementos que implicam as escolhas para os cargos de prefeito e governador, e para o cargo de deputado estadual no âmbito Legislativo, cobrem um terreno variado de práticas políticas locais, imagens e vinculações partidárias capazes de fornecer respostas às indagações sobre o curso das preferências partidárias no estado ${ }^{1}$.

A caracterização do sistema partidário paulista e de sua dinâmica de funcionamento desde o início da democratização está já feita em vários trabalhos que afirmam que a implantação do multipartidarismo no país estabeleceu-se sob o formato específico das políticas estaduais e deu certa continuidade às distinções dos subsistemas presentes no período anterior ao interregno do bipartidarismo (Lima Jr., 1993). No caso paulista, o sistema seguiu o curso combinado, pluralista, polarizado e moderado, em um modelo em que o amplo terreno político de múltiplas legendas se desenvolve com base no equilíbrio de poucos partidos efetivos e blocos ideológicos delimitados (Lima Jr, 1993; Figueiredo e Jorge, 1997; Braga e Kinzo, 2007; Ferreira, Batista e Stabile, 2008).

Uma análise da dinâmica do sistema partidário paulista iniciado em 1986 aponta dois principais períodos de organização da política: no primeiro, entre 1986 e 1994, três polos organizam a dinâmica do siste- 
ma, encabeçados pelo PMDB, pelo malufismo acolhido no $\mathrm{PDS} / \mathrm{PPB} / \mathrm{PPR} / \mathrm{PP}$ e pelo PT que, de forma crescente, liderou as preferências à esquerda do bloco oposicionista ao governo estadual. A partir de 1994, as transformações observadas no nível nacional refletiram no cenário estadual, aprofundaram as bases de consolidação do peessedebismo, mas adquiriram uma coloração própria com a partilha política entre PSDB e PT.

Assim, os dados mostram claramente a substituição da preferência peemedebista pelo voto no PSDB e no PT a partir de 1998, com ênfase para a eleição majoritária para o governo do estado. Para o PDS, o declínio já era observado desde o início da democratização, seja pela divisão de espaço com o PFL no nível local, seja pela força de competição dos demais partidos (Gráficos 1 e 3).

No nível local, os dados mostram que, apesar da queda do domínio peemedebista nas prefeituras do interior já desde 1992, em detrimento do avanço do PSDB, o PMDB mantém-se como segunda força estadual até a eleição de 2004, concorrendo claramente com o avanço do PFL/DEM, e apenas em 2008 cai para a terceira posição (Gráfico 2).

Gráfico 1

Votação para Governador por Partido (\%)

(1982-2010)



Fonte: TSE, TRE-SP e SEADE. 
Rachel Meneguello e Fernando Bizzarro Neto

Gráfico 2

Prefeitos Eleitos por Partido (\%)

(1988-2008)

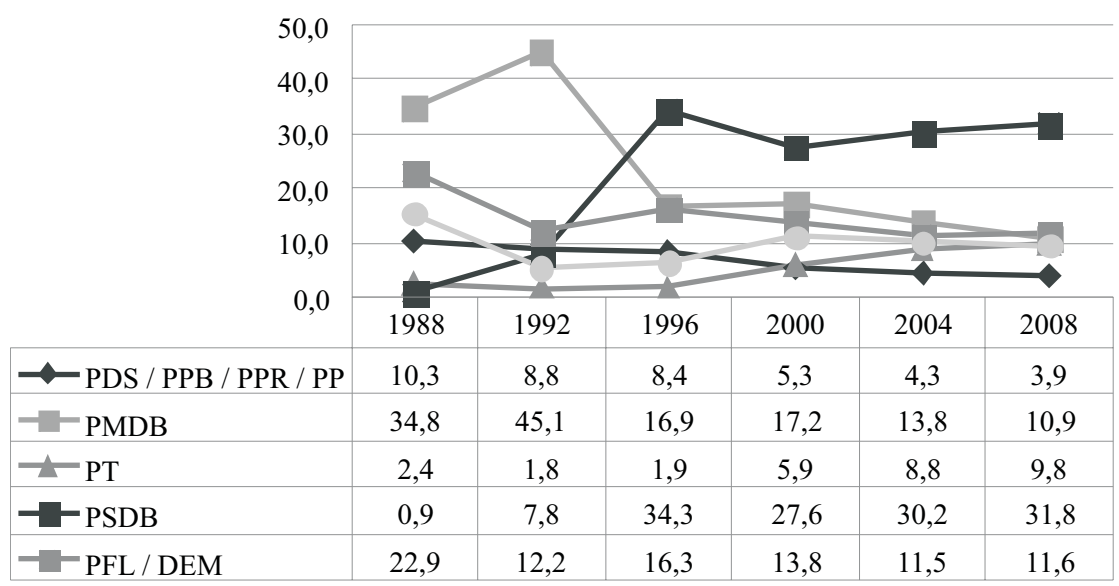

Fonte: TSE, TRE-SP e SEADE.

Gráfico 3

Votação Deputado Estadual por Partido (\%)

(1982-2010)



Fonte: TSE, TRE-SP e SEADE. 
O aumento da competitividade eleitoral é um ponto a destacar. Os dados mostram que, a partir de 1990, o quadro paulista passou a traduzir as mudanças do sistema nacional na mesma direção que a maioria dos estados: a concentração de forças nas eleições majoritárias e a fragmentação partidária nas eleições proporcionais (Braga e Kinzo, 2007) - no segundo ponto com uma intensidade muito maior em São Paulo. O aumento em dobro do número de partidos parlamentares, de 7 em 1986, para 15 em 2010, e os altos índices de volatilidade eleitoral em todos os anos desde 1994, muito acima dos indicadores nacionais para a Câmara de Deputados (Meneguello, 2011), ilustram a especificidade do quadro paulista a que chamamos atenção (Tabela 1).

Para as eleições majoritárias para o governo estadual, o duelo PSDB/PT, que passou a organizar a política nacional desde 1994, só teve sua tradução local a partir de 2002, quando, inclusive, os dois grupos passaram a concentrar mais de dois terços das votações no primeiro turno eleitoral, em cenários de candidaturas numerosas, 15 em 2002 e 16 em 2006, bem acima dos quadros de candidaturas nacionais nesses pleitos (6 candidaturas, em 2002 e em 2006, ver Meneguello, 2011:455) (Tabela 2).

Tabela 1

Indicadores de Competição Política - Legislativo Estadual

\begin{tabular}{l|c|c|c|c|c|c|c|c}
\hline & $\mathbf{1 9 8 2}$ & $\mathbf{1 9 8 6}$ & $\mathbf{1 9 9 0}$ & $\mathbf{1 9 9 4}$ & $\mathbf{1 9 9 8}$ & $\mathbf{2 0 0 2}$ & $\mathbf{2 0 0 6}$ & $\mathbf{2 0 1 0}$ \\
\hline Número médio de candidatos & 5,8 & 10,1 & $*$ & 8,5 & 13,5 & 15,4 & 16,2 & 19,0 \\
Índice de competitividade & 1,9 & 4,0 & $*$ & 3,3 & 5,7 & 6,7 & 7,1 & 9,5 \\
Número efetivo de partidos & 2,9 & 3,8 & 7,3 & 6,9 & 8,3 & 8 & 6,9 & 6,5 \\
Número de partidos parlamentares & 4 & 7 & 13 & 14 & 14 & 16 & 14 & 15 \\
Fracionalização & 0,65 & 0,74 & 0,86 & 0,86 & 0,88 & 0,88 & 0,86 & 0,84 \\
Volatilidade & & 21,5 & 29,7 & 19,3 & 22,7 & 21,7 & 23,2 & 21,4 \\
\hline
\end{tabular}

Fonte: Elaboração a partir de dados de www.ucam.edu.br/leex; TSE; TRE-SP e SEADE.

* Não há dados confiáveis.

Com relação à organização do quadro partidário, uma análise sobre a reacomodação das elites (candidatos) nos seis principais partidos (PMDB, PDS, PT, PDT, PTB, PFL) no período entre 1988 e 1996, ajuda a compreender o fragmentado terreno político local e sua capacidade de organização diante do volumoso número de partidos estabelecido no estado. Nesse período, do total de candidatos lançados por esses partidos nas eleições de 1986 e 1988 e que se recandidataram entre 1990 e 1996, apenas 51,9\% se mantiveram na mesma legenda. PT e PMDB são 


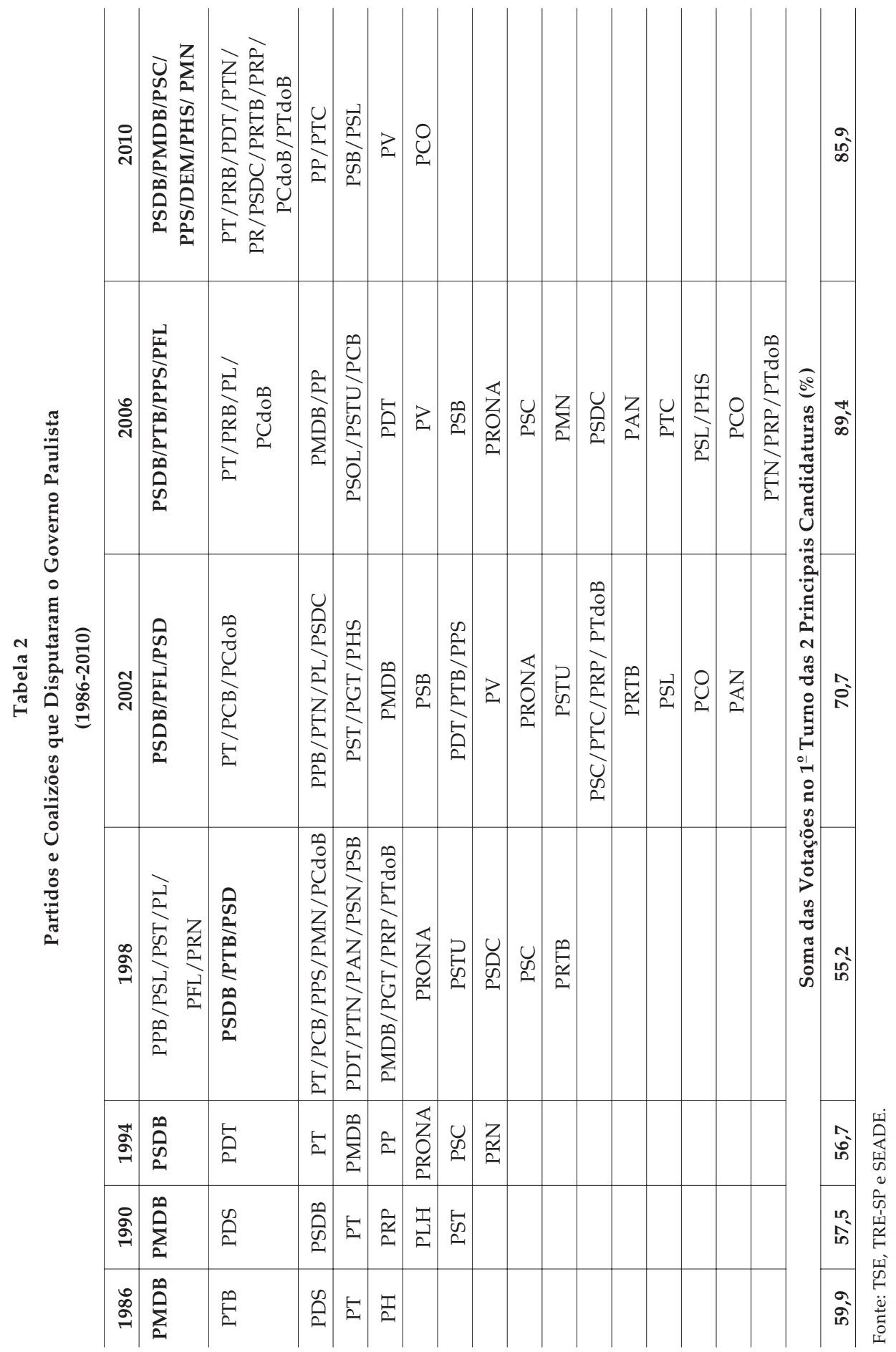


os partidos que relançaram o maior número de candidaturas, $74,8 \%$ para o primeiro e $61,1 \%$ para o segundo. O maior êxodo de candidatos ocorreu no PDT, que manteve apenas $31,1 \%$ de candidatos entre as eleições. Os dados mostram um intenso movimento de candidatos das principais siglas para as 25 novas legendas, inclusive entre polos ideológicos, embora nesse caso com menor intensidade. PMDB e PSDB foram os partidos que mais absorveram candidatos de outras legendas nesse período de reacomodação, mas com destaque especial para o PSDB, que constituiu boa parte do conjunto de candidaturas lançadas em 1996, quando cresceu consideravelmente de $7,8 \%$ para $34,5 \%$ das prefeituras, a partir da migração de candidatos vindos de todos os principais partidos (Tabela 3).

Esses dados de migração de candidaturas partidárias, embora limitados ao início do período estudado, sugerem investigar o grau de consolidação de preferências dos eleitores. Uma análise das associações entre as votações partidárias entre eleições para governo, prefeituras e legislativo estadual resulta em um panorama - ainda que simples - do grau de enraizamento partidário, visto a partir do embasamento de preferências, um aspecto essencial para avaliarmos a capacidade de fortalecimento das legendas e constituição do sistema político estadual. Interessa-nos especificamente mostrar o potencial de formação de bases eleitorais dos principais partidos PSDB, PMDB, PT, PDS/PP, $\mathrm{PFL} / \mathrm{DEM}$ e PTB. Os dados analisados são as porcentagens de votações partidárias por município para cada eleição (Tabelas 4, 5 e 6).

Os dados das Tabelas 4, 5 e $6^{2}$ mostram que, para o PT, as correlações são notáveis. Não é novidade afirmar o partido como legenda com bases partidárias sólidas, mas os dados se destacam: até 2002, as correlações entre eleições contíguas para o governo são bastante altas, como 0,92 entre 1990 e 1994, 0,83 entre 1994 e 1998, e 0,76 entre 1998 e 2002. Sobressaem ainda mais os dados de manutenção de bases no tempo: a associação entre as votações para o governo em 1986 e 1998 é $r=0,76$, um indicador bastante alto. A associação entre votações também é significativa entre 2006 e 2010, quando o partido lançou o mesmo candidato ao governo (Aloisio Mercadante). No âmbito das eleições para prefeito, o partido mostra na primeira eleição do novo período democrático uma forte associação com as votações que obteve em sua primeira eleição local no estado em $1982(0,64)$, mas declinam nas eleições seguintes. Apesar de mais baixas, as associações estão em torno de $r=$ 0,5 , um valor bastante razoável quando se trata de decisão eleitoral. É 







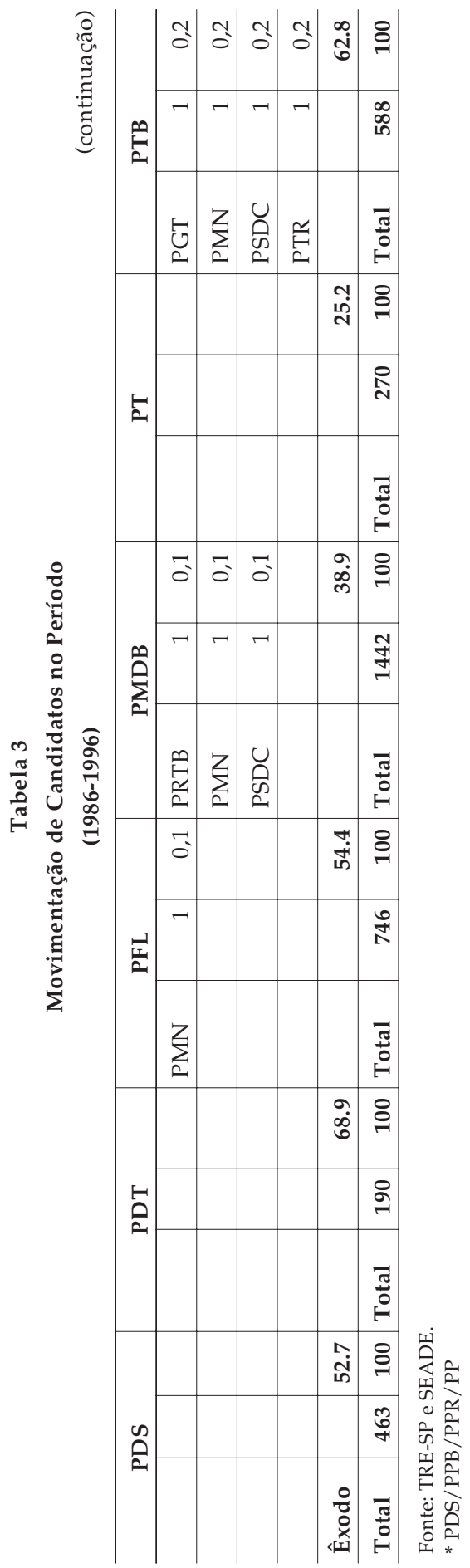


bom lembrar que, em todo o período, o partido não consegue obter mais que $10 \%$ das prefeituras do estado, comprovando as dificuldades para seu embasamento local. Ao contrário, quanto às votações para a Assembleia Legislativa, a partir da eleição de 2002 a associação entre eleições ganha valores significativos, acima de 0,5 , e entre o par de eleição entre 2006 e 2010, chega a $r=0,64$.

O PDS (e as várias nomenclaturas que adquiriu ao longo do período) apresenta correlações significativas em eleições para governo, tanto contíguas quanto distantes no tempo, nas quais Paulo Maluf participou como candidato. Assim, entre 1986 e 1990, as votações estão associadas com um coeficiente $r=0,58$, um valor que aumenta para $r=0,62$ para o par de eleições de 1990 e 1998, e depois atinge $r=0,6$ para as eleições de 1998 e 2002. Esses são dados indicativos de que as bases do partido se estabeleceram no espaço e no tempo sob o crivo da liderança malufista. De toda forma, a fraqueza das associações reflete a perda pelo partido do espaço político no estado. No nível local, por exemplo, há uma queda de mais de $50 \%$ do número de prefeituras nos 20 anos analisados e, de fato, a única associação significativa encontrada ocorre entre 2004 e 2008, com r = 0,53. No âmbito legislativo, observa-se a mesma fraqueza das associações das votações entre eleições.

No caso do PMDB, sua forte presença no estado desde 1986 (e antes, inclusive) até 1994, quando perdeu o domínio político para o PSDB, não resultou em bases mais consolidadas de preferências eleitorais. $O$ conjunto de correlações médias entre as votações partidárias que apresenta no período fica em torno de $r=0,5$. As melhores correlações ocorrem entre eleições contíguas para o governo do estado, notadamente entre 1986 e 1990, e entre 1998 e 2002 (para ambos os pares, $r=0,5$ ). Mas destaca-se a notável associação encontrada entre as eleições nas quais Orestes Quércia participou como candidato ao governo, 1998 e 2006, em que a associação é muito significativa, $r=0,81$, sugerindo, assim como no caso do PDS de Maluf, a formação de bases mais estreitamente vinculadas àquela liderança específica. Entre as eleições locais, a fraqueza dos coeficientes de associação refletem a forte queda do partido no estado, sobretudo a partir de 1996, quando perdeu mais da metade das prefeituras, e entra em declínio até o final do período. A associação de maior relevância no nível local ocorre entre 2004 e 2008, mas ainda assim um coeficiente baixo, $r=0,47$. As associações para o voto no âmbito legislativo acompanham esse mesmo declínio, traduzidas nos baixos valores de $\mathrm{r}$. 
Para o PSDB, as correlações encontradas são significativas apenas para as votações ao governo do estado. A partir de 1998, os pares de eleições contíguas mostram associações importantes, 0,54 entre 1998 e 2002, 0,51 entre 2002 e 2006, e 0,80 entre 2006 e 2010, quando então o partido definitivamente consolidou o processo de hegemonia eleitoral no estado. No nível local, ao contrário, os coeficientes não atingem o valor 0,4 , refletindo o processo predominantemente desconcentrado pelo qual suas bases se estabeleceram; é importante lembrar que desde 1996 o partido detém um terço das prefeituras do estado. No âmbito legislativo, as mesmas baixas correlações se repetem na maior parte do período, apenas alterando entre 2006 e 2010, quando as votações se associam em 0,48 .

Finalmente, para o PFL/DEM e para o PTB, os cenários encontrados são muito semelhantes. Os dois partidos não estabeleceram bases capazes de sustentar candidaturas ao governo do estado no período apenas o PTB lançou candidato em 1986 e, depois, em 2002. A "vocação local" das duas legendas se traduz em algumas associações no período: para o PTB, entre 1992 e 1996, com r = 0,60, e entre 1996 e 2000, com r = 0,45; para o DEM, entre 2000 e 2004, e entre 2004 e 2008, ambos com r $=0,55$. No âmbito legislativo, as associações também são frágeis, e apenas no final do período o DEM apresenta correlação mais importante, com $r=0,51$ entre 2006 e 2010 .

Os dados indicam que, apesar do volumoso quadro partidário, as estruturas dos principais partidos foram capazes de estabelecer algum grau de enraizamento de preferências, sobretudo observado em eleições majoritárias. Não é coincidência, portanto, que mesmo com a fragmentação do sistema partidário a partir de 1988, os principais partidos do estado no período sejam ainda aqueles fundados no início do processo de democratização. No nível das votações para o legislativo, o quadro é distinto, mas convém lembrar os dados apresentados anteriormente na Tabela 1 para eleições legislativas, a pontando que as condições para a constituição de preferências são realmente adversas, dadas a forte fragmentação partidária, a magnitude elevada do distrito e a dispersão das preferências do eleitor entre pleitos, traduzidas nos altos índices de volatilidade. Apesar dessa clara dispersão, quando analisadas segundo sua distribuição espacial, será possível identificar alguns redutos específicos das votações para o legislativo para os partidos (item A Trajetória das Votações: Distribuição Regional deste artigo). 
Rachel Meneguello e Fernando Bizzarro Neto

Tabela 4

Correlações $r$ de Pearson para as Votações para o Governo entre 1986 e 2010

\begin{tabular}{|c|c|c|c|c|c|c|}
\hline \multicolumn{7}{|c|}{ PT } \\
\hline & 1990 & 1994 & 1998 & 2002 & 2006 & 2010 \\
\hline 1986 & 0,9 & 0,85 & 0,76 & 0,56 & 0,38 & \\
\hline 1990 & & 0,92 & 0,82 & 0,63 & 0,43 & 0,10 \\
\hline 1994 & & & 0,83 & 0,68 & 0,48 & 0,20 \\
\hline 1998 & & & & 0,76 & 0,43 & 0,13 \\
\hline 2002 & & & & & 0,55 & 0,32 \\
\hline 2006 & & & & & & 0,78 \\
\hline \multicolumn{7}{|c|}{ PMDB* } \\
\hline & 1990 & 1994 & 1998 & 2002 & 2006 & 2010 \\
\hline 1986 & 0,49 & 0,24 & 0,30 & 0,27 & 0,15 & \\
\hline 1990 & & 0,45 & 0,56 & 0,34 & 0,44 & \\
\hline 1994 & & & 0,28 & 0,15 & 0,16 & \\
\hline 1998 & & & & 0,50 & 0,81 & \\
\hline 2002 & & & & & 0,43 & \\
\hline 2006 & & & & & & \\
\hline \multicolumn{7}{|c|}{ PDS/PP*** } \\
\hline & 1990 & 1994 & 1998 & 2002 & 2006 & 2010 \\
\hline 1986 & 0,57 & & 0,48 & & & \\
\hline 1990 & & 0,12 & 0,63 & & & \\
\hline 1994 & & & 0,13 & & & \\
\hline 1998 & & & & 0,60 & & \\
\hline \multicolumn{7}{|l|}{2002} \\
\hline 2006 & & & & & & \\
\hline
\end{tabular}

\begin{tabular}{|c|c|c|c|c|c|c|}
\hline \multicolumn{7}{|c|}{ PSDB } \\
\hline & 1990 & 1994 & 1998 & 2002 & 2006 & 2010 \\
\hline \multicolumn{7}{|l|}{1986} \\
\hline 1990 & & 0,3 & & & & \\
\hline 1994 & & & 0,21 & 0,14 & 0,26 & 0,18 \\
\hline 1998 & & & & 0,54 & 0,28 & 0,20 \\
\hline 2002 & & & & & 0,51 & 0,50 \\
\hline 2006 & & & & & & 0,80 \\
\hline \multicolumn{7}{|c|}{ PTB ** } \\
\hline & & & & 2002 & & \\
\hline 1986 & & & & 0,14 & & \\
\hline 1990 & & & & & & \\
\hline 1994 & & & & & & \\
\hline 1998 & & & & & & \\
\hline 2002 & & & & & & \\
\hline 2006 & & & & & & \\
\hline
\end{tabular}

Elaboração dos autores.

Apresentados apenas coeficientes significantes a $0,01^{3}$.

*PMDB não lançou candidato em 2010;

** PTB apenas lançou candidato em 1986 e 2002;

*** PDS/PP não lançou candidato em 2006.

\section{MUDANÇAS ESTRUTURAIS E GEOGRAFIA ELEITORAL}

\section{Breve Cenário e Pressupostos}

Os últimos trinta anos são marcados por fortes transformações sociodemográficas no estado, dentre as quais o crescimento das cidades e o processo de urbanização tiveram uma dinâmica notável. A população das maiores cidades de São Paulo (com mais de 100 mil habitantes) au- 
Contexto e Competição na Política Paulista




Rachel Meneguello e Fernando Bizzarro Neto

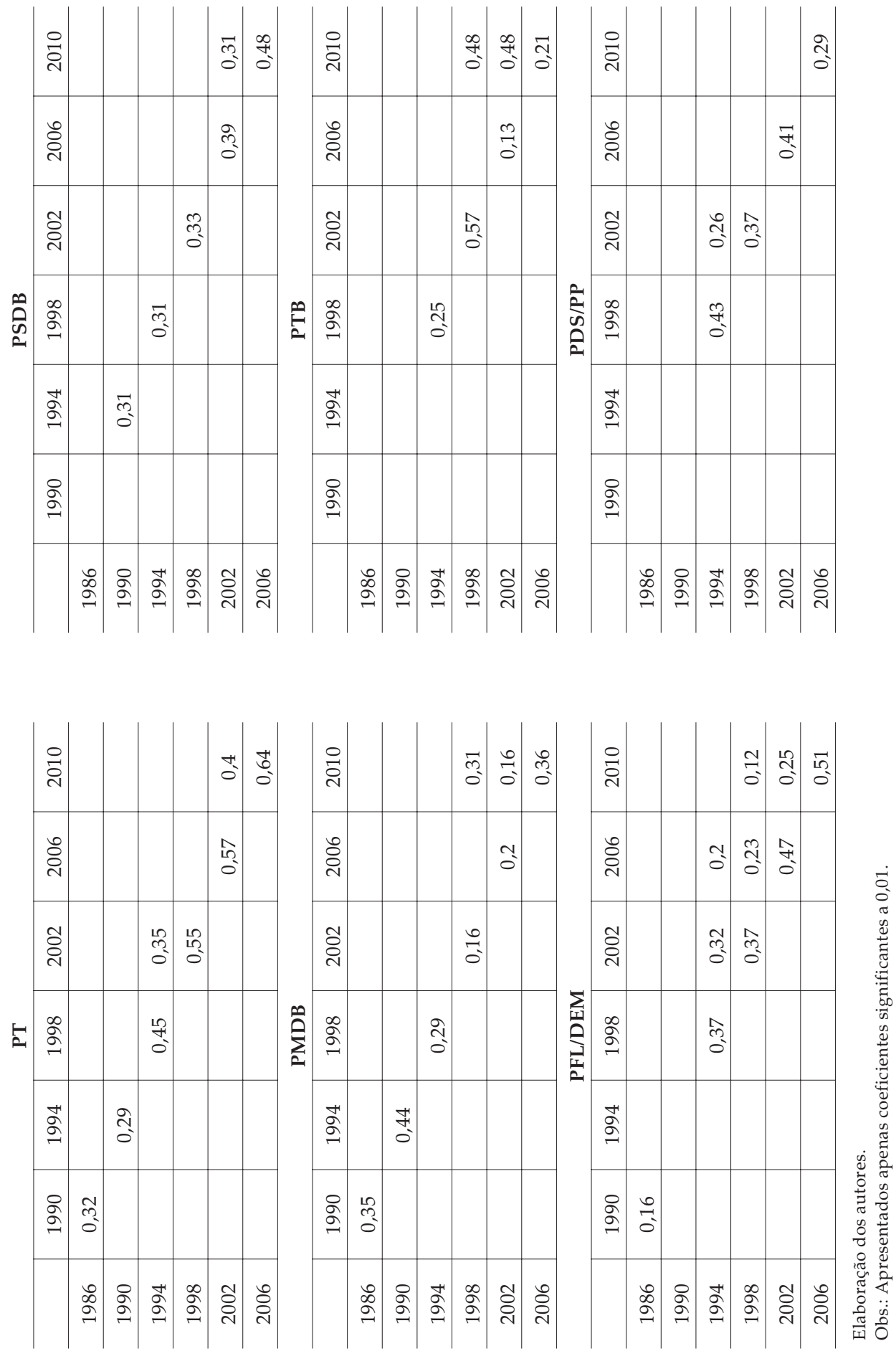


mentou de maneira muito mais significativa que a população residente nos demais municípios. A isso soma-se o fato de que, entre 1980 e 2010, as cidades que possuíam a maioria de suas populações vivendo em áreas rurais (considerados os municípios com até $50 \%$ da população urbana) diminuem de $34,1 \%$ para $4,2 \%$ do total de municípios no estado.

Além disso, alguns indicadores básicos apontam para uma trajetória de transformações importantes no modelo de desenvolvimento do estado, iniciada na década de 1990, em que o perfil agrícola de quase metade da população economicamente ativa decresceu até atingir menos de 19\% em 2010; a população economicamente ativa (PEA) industrial teve apenas um crescimento moderado e passou a representar menos de $25 \%$, e a PEA de serviços, abrangendo mais da metade da PEA estadual $(57,7 \%)$, passou a marcar o perfil econômico predominante estadual no fim do período (Tabela 7). Também é significativo o aumento da população escolarizada, fazendo a taxa de analfabetismo no estado cair de 10\% para 5\% em 30 anos (Gráfico 4). Em 2010, o estado chega a uma população de mais de 41 milhões de habitantes e um eleitorado de mais de 30 milhões de cidadãos, o maior do país.

Nesta segunda parte do artigo os dados estão apresentados e analisados segundo sua distribuição no estado, agregados por região administrativa (Mapa 1). As 15 regiões administrativas agregam os $645 \mathrm{mu}-$ nicípios, e sua caracterização segundo suas vocações econômicas e demográficas dá base a um de nossos argumentos centrais nesse artigo, qual seja, que a política paulista responde em boa medida aos efeitos do contexto socioeconômico e da variável regional, em que as relações entre centro e periferia exercem papel importante na formação de preferências. Apresentamos nosso argumento com mais detalhes a seguir.

Uma descrição geral da evolução populacional, da taxa de analfabetismo e das taxas de ocupação da PEA nos três setores básicos, indústria, agricultura e serviços ${ }^{4}$ mostra alguns destaques.

As regiões de Barretos e Marília chegam ao final da década de 2000 como as de maior ocupação de mão de obra agrícola; Campinas e São Paulo, as de maior ocupação industrial, assim como as de maior concentração populacional, somando $63 \%$ do estado; Santos e São Paulo, como as regiões de maior ocupação em serviços. As regiões com menor taxa de urbanização ao final do período são Registro e Sorocaba, sendo Registro a região menos populosa, com apenas $0,65 \%$ da população do 


\section{Gráfico 4 - Indicadores socioeconômicos SP (1980 - 2010)}

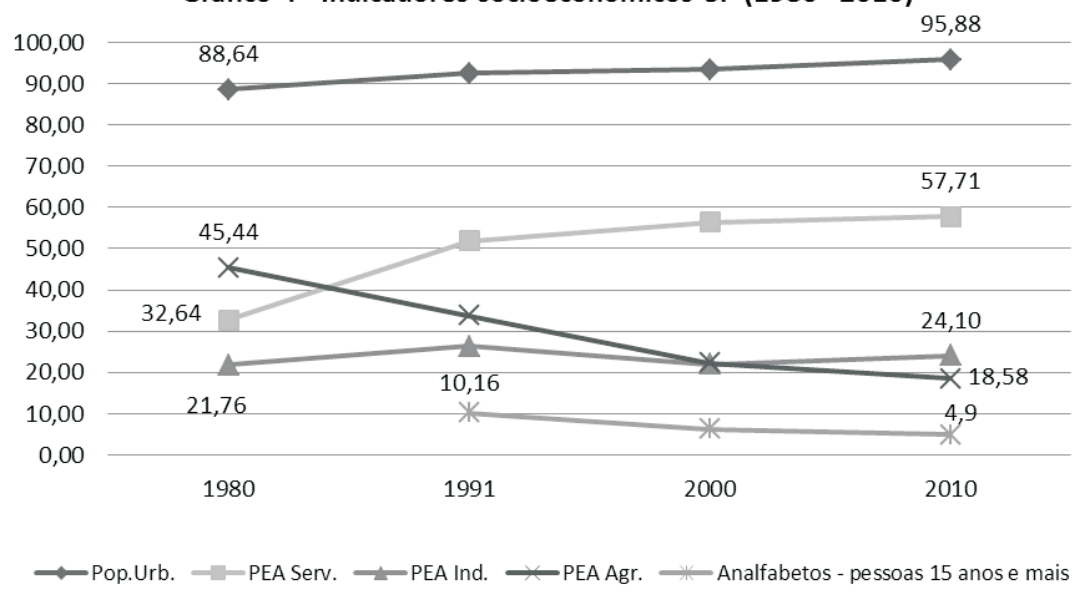

\section{Mapa 1}

Regiões Administrativas do Estado de São Paulo

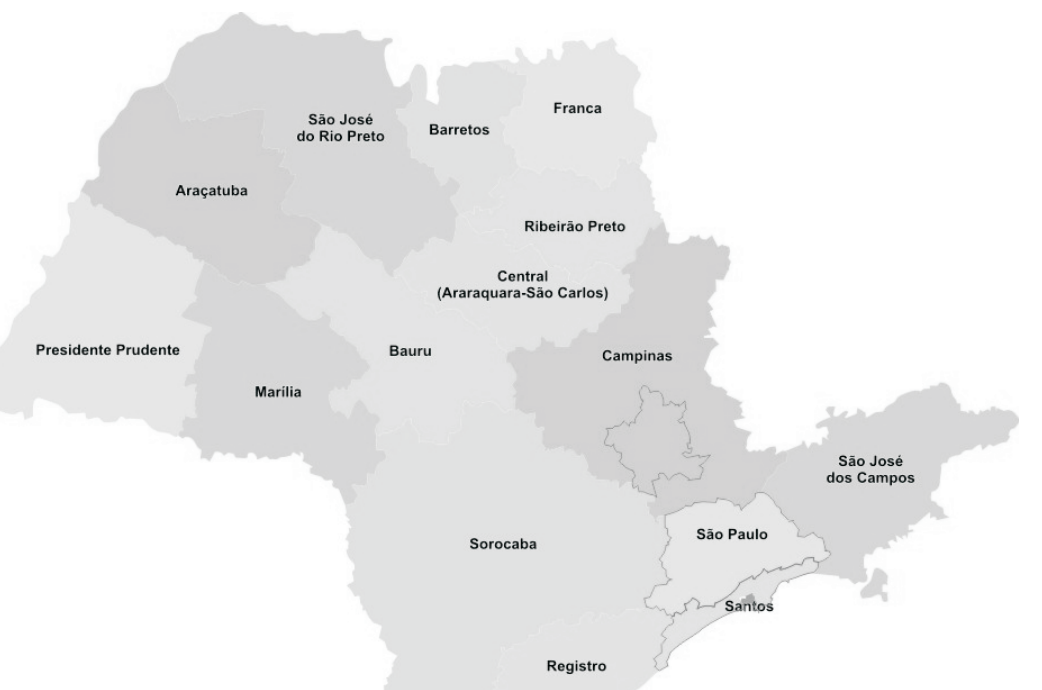

Fonte: Secretaria de Planejamento e Desenvolvimento Regional do Estado de São Paulo. 


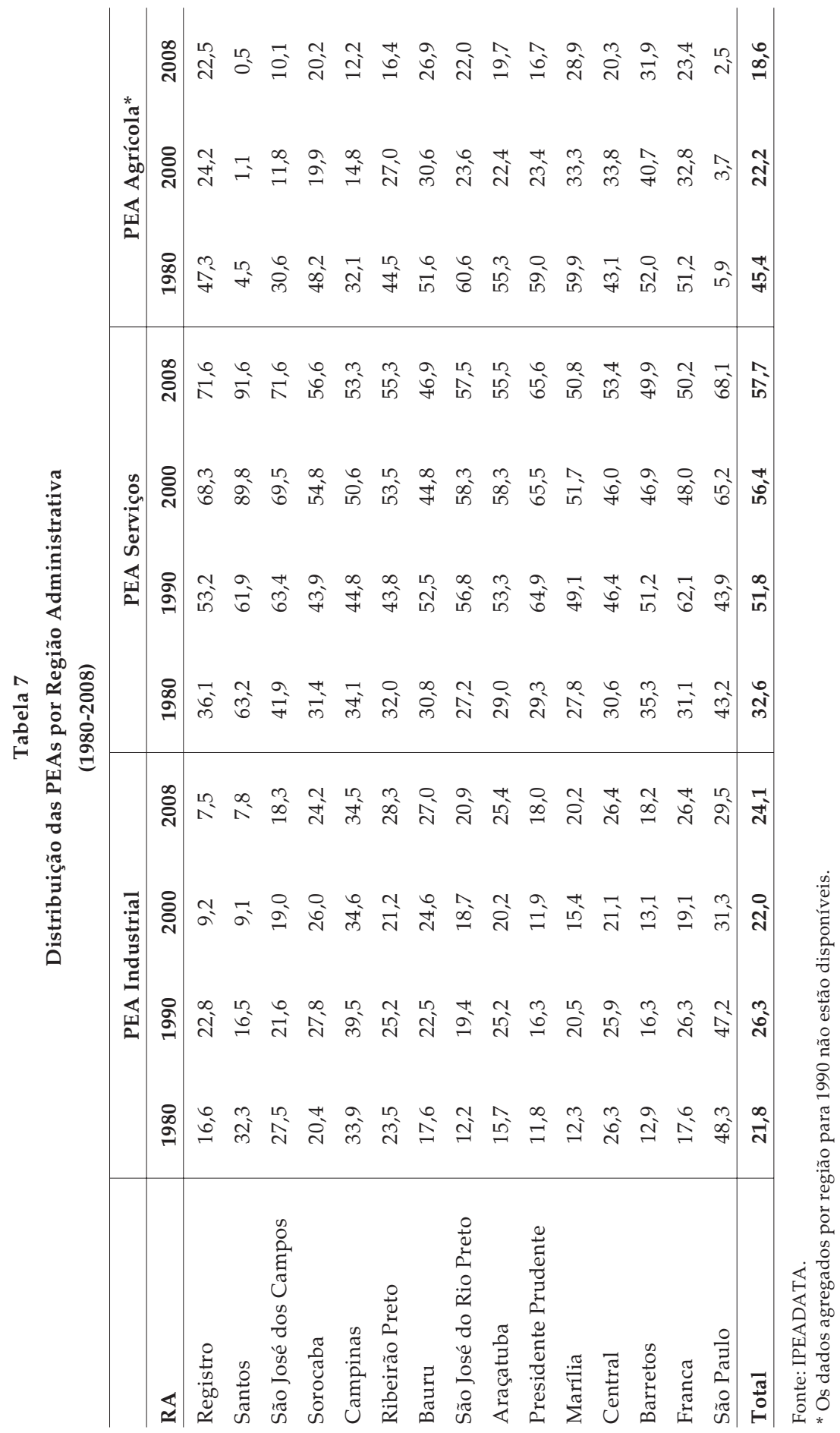


estado em 2010. Com relação à população escolarizada, em algumas regiões as transformações são importantes. Registro e Presidente Prudente apresentam as maiores taxas de analfabetismo no início da década de 1990, respectivamente 19,8\% e 19,6\%, que decrescem em 2000 para $12,6 \%$ e $14 \%$. Santos e São Paulo são as regiões com as maiores taxas de população escolarizada e mostram em 2000 taxas de analfabetismo de 7 e $8 \%$ respectivamente (Tabela 7 ).

Quanto à distribuição da população, não houve alterações importantes ao longo do período, sendo que as duas transformações mais significativas ocorreram com a diminuição da participação da região de São Paulo, que em 2010 deixou de acolher mais da metade da população estadual, e o aumento da população da região de Campinas, que ao final do período contribui com $15 \%$ da população total (Tabela 8).

Um dos objetivos deste artigo está em identificar em que medida a política paulista respondeu nesse período aos efeitos de determinantes contextuais que caracterizam seu território político. O ponto de partida da indagação está em Lipset e Rokkan (1967), assim como a proposição de que preferências políticas refletem as distinções sociais. Mesmo cientes do estágio avançado que esse debate adquiriu nas últimas décadas (Evans, 1999; Karvonen e Kuhnle, 2005; Best, 2011), do espaço ocupado pela discussão pós-materialista (Inglehart, 1997) e das interpretações feitas à "freezing hypothesis" (Mair, 2005), assumimos o que Lipset sugere quanto ao fato de que as divisões sociais se estabelecem traduzindo processos dinâmicos sociais, econômicos e políticos, e de que as fontes das clivagens identificadas na primeira metade do século XX, produzidas pela dinâmica do mundo urbano e industrial e das relações entre centro e periferia, têm, em alguma medida, continuidade na sociedade contemporânea pós-industrial (Lipset, 2001). Nessa direção, este artigo investiga em que medida a trajetória das preferências político-partidárias paulistas estiveram associadas ao padrão agregado de desenvolvimento do estado, entendido a partir especificamente do perfil da população ocupada nos setores básicos da economia, a taxa de escolaridade e o tamanho dos municípios.

Além desses supostos, o enfoque realizado segue o caminho dos estudos da geografia eleitoral. A literatura internacional sobre geografia eleitoral sustenta o efeito de contextos sobre a formação de preferências políticas, apontando que indivíduos decidem eleitoralmente sob influência do meio em que sua vida cotidiana está engajada (Taylor e 
Tabela 8

População por Região Administrativa (\% do total)

(1980-2010)

\begin{tabular}{l|c|c|c|c}
\hline & $\mathbf{1 9 8 0}$ & $\mathbf{1 9 9 0}$ & $\mathbf{2 0 0 0}$ & $\mathbf{2 0 1 0}$ \\
\hline Registro & 0,7 & 0,7 & 0,7 & 0,7 \\
Santos & 3,8 & 3,9 & 4,0 & 4,0 \\
São José dos Campos & 4,9 & 5,2 & 5,4 & 5,5 \\
Sorocaba & 6,0 & 6,4 & 6,7 & 6,8 \\
Campinas & 12,8 & 13,8 & 14,6 & 15,2 \\
Ribeirão Preto & 2,6 & 2,8 & 2,9 & 3,0 \\
Bauru & 2,7 & 2,6 & 2,6 & 2,6 \\
São José do Rio Preto & 3,8 & 3,6 & 3,5 & 3,5 \\
Araçatuba & 2,1 & 2,0 & 1,8 & 1,8 \\
Presidente Prudente & 2,7 & 2,4 & 2,1 & 2,0 \\
Marília & 2,7 & 2,52 & 2,4 & 2,3 \\
Central & 2,2 & 2,30 & 2,3 & 2,3 \\
Barretos & 1,1 & 1,1 & 1,1 & 1,0 \\
Franca & 1,6 & 1,7 & 1,7 & 1,7 \\
São Paulo & 50,3 & 49,0 & 48,3 & 47,7 \\
\hline Total População Estado & $\mathbf{2 9 . 5 1 7 . 2 1}$ & $\mathbf{3 0 . 7 8 3 . 1 0 8}$ & 33.240 .084 & $\mathbf{4 1 . 2 1 1 . 6 1 6}$ \\
\hline Total Eleitorado Estado & $\mathbf{1 6 . 8 9 0 . 8 1 7}$ & $\mathbf{1 8 . 7 2 7 . 0 1 4}$ & $\mathbf{2 3 . 3 2 1 . 0 3 4}$ & $\mathbf{3 0 . 3 0 1 . 3 3 3}$ \\
\hline
\end{tabular}

Johnston, 1979; Agnew, 1996; Johnston e Pattie, 2006). Apesar das transformações socioeconômicas, estruturais e culturais da sociedade contemporânea, sustenta-se que a variável regional ainda exerce um papel importante na explicação dos padrões de votação, e que implica, ademais, em efeitos de vizinhança, ou de propagação política, que traduziriam a articulação de fatores estruturais e de socialização em contextos geograficamente próximos.

No caso brasileiro, Lima Jr. (1993) já havia partido dessas mesmas indagações com o objetivo de investigar, em nível nacional, em que medida o desenho do sistema partidário altamente fragmentado resultaria de certo determinismo social. $\mathrm{O}$ autor não encontrou vinculação significativa entre os fenômenos, mas seus dados apontaram que a complexidade da vida social dos grandes centros estava em alguma medida relacionada à fragmentação eleitoral.

No caso paulista, Faria (1975) deu o ponto de partida para investigar no estado de São Paulo o impacto de processos socioeconômicos con- 
textualmente estabelecidos sobre as transformações políticas. O estudo dos resultados da eleição de 1974 e do notável desempenho do partido de oposição, segundo indicadores socioeconômicos, mostrou que o MDB beneficiou-se dos contextos de microrregiões do estado em que o processo de desenvolvimento agregado deu-se de forma acentuada.

Em um breve estudo estatístico sobre a caracterização das bases sociais do PT, PDS, PMDB e PTB no estado nas eleições de 1982 e 1986, Gonçalves (1998) mostrou, fazendo uso de análise multivariada, a associação das votações partidárias para o governo estadual a contextos específicos, localizando terrenos de preferências conservadoras e progressistas, bem como a transformação da distribuição dos votos entre uma eleição e outra. Assim, em 1982, verificou-se o forte predomínio da votação do PDS em áreas rurais, a força do PMDB em municípios altamente urbanizados e com índices de escolaridade altos, enquanto as votações do PT e PTB localizavam-se em municípios altamente industrializados. Em 1986, ocorreu o "espalhamento" do PMDB para o interior do estado, alcançando inclusive municípios e regiões antes associadas ao voto conservador do PDS. PT e PTB, por sua vez, aprofundaram sua presença nos municípios de perfil industrial. Seguindo esse caminho, analisamos a trajetória das votações a partir de 1986 para esses principais partidos, e encontramos dados que permitem sugerir a manutenção ao longo do tempo, mas com variações, da associação entre as votações partidárias e contextos específicos do estado. É o que mostramos a seguir.

\section{A Trajetória das Votações: Fatores Socioeconômicos}

A análise das associações $r$ de Pearson entre as variáveis estruturais socioeconômicas e as porcentagens de votação para cargos e partidos, selecionados os de maior votação no período, apontam que, com o decorrer do período, mais notadamente a partir da eleição de 2006 para governador, as associações entre votações partidárias e variáveis socioeconômicas perdem força, sem desaparecer, traduzindo o espalhamento das preferências políticas no estado, antes mais claramente associadas a indicadores socioeconômicos específicos. Os dados para as votações ao governo sustentam nosso argumento (Tabela 9).

Inicialmente, destaca-se a notável manutenção da associação das votações do PT desde a eleição de 1990 até 2002, com municípios de perfil industrial. Essa associação, presente de forma significativa desde a 
primeira eleição do partido no estado em 1982, mantém valores por volta de $r=0,44$ até 1998, e perde força nas eleições seguintes, sugerindo a presença de outras variáveis de natureza distinta na formação das preferências. Em 2010, a associação que tradicionalmente marca parte do perfil do voto petista se inverte, e o voto para o candidato do gover-

Tabela 9

Correlações r de Pearson entre Votações Partidárias e Fatores Demográficos e Socioeconômicos nas Eleições para Governador em São Paulo (1990-2010)

\begin{tabular}{|c|c|c|c|c|c|}
\hline & \multicolumn{4}{|c|}{1990} & \\
\hline & PDS & PMDB & PSDB & PT & \\
\hline População 1990 & -.003 & -.13 & .26 & .20 & \\
\hline PEA Agr. 1990 & -.013 & .16 & -.25 & -.21 & \\
\hline PEA Ind. 1990 & -.13 & -.21 & .25 & .44 & \\
\hline PEA Serv. 1990 & .15 & .10 & -.13 & -.31 & \\
\hline \multirow{3}{*}{ Tx. Analf. 1991} & .17 & .23 & -.56 & -.60 & \\
\hline & \multicolumn{5}{|c|}{1994} \\
\hline & PP & PMDB & PSDB & PT & PDT \\
\hline População 1990 & .13 & -.12 & .07 & .19 & .12 \\
\hline PEA Agr. 1990 & -.09 & .18 & -.16 & -.19 & -.14 \\
\hline PEA Ind. 1990 & .37 & -.23 & -.11 & .44 & .31 \\
\hline PEA Serv. 1990 & -.31 & .12 & .15 & -.31 & -.21 \\
\hline \multirow[t]{3}{*}{ Tx. Analf. 1991} & -.45 & .35 & -.21 & -.54 & -.37 \\
\hline & \multicolumn{5}{|c|}{1998} \\
\hline & PP & PMDB & PSDB & PT & PDT \\
\hline População 1990 & -.06 & -.07 & -.03 & .17 & .05 \\
\hline PEA Agr. 1990 & .07 & .22 & .03 & -.30 & -.18 \\
\hline PEA Ind. 1990 & -.18 & -.03 & -.14 & .42 & .20 \\
\hline PEA Serv. 1990 & .08 & -.19 & .13 & -.04 & -.07 \\
\hline \multirow[t]{3}{*}{ Tx. Analf. 1991} & .21 & .09 & .19 & -.57 & -.16 \\
\hline & \multicolumn{4}{|c|}{2002} & \\
\hline & PP & PMDB & PSDB & PT & \\
\hline População 2000 & -.01 & -.06 & -.09 & .10 & \\
\hline PEA Agr. 2000 & .06 & .18 & .17 & -.21 & \\
\hline PEA Ind. 2000 & -.08 & -.01 & -.26 & .33 & \\
\hline PEA Serv. 2000 & .00 & -.17 & .09 & -.10 & \\
\hline Tx. Analf. 2000 & .09 & .09 & .33 & -.41 & \\
\hline
\end{tabular}


Rachel Meneguello e Fernando Bizzarro Neto

Tabela 9

Correlações $r$ de Pearson entre Votações Partidárias e Fatores Demográficos e Socioeconômicos nas Eleições para Governador em São Paulo

(1990-2010)

(continuação)

\begin{tabular}{l|c|c|c}
\hline & \multicolumn{3}{|c}{ 2006 } \\
\hline População 2000 & -.01 & -.13 & .10 \\
PEA Agr. 2000 & .06 & .13 & -.09 \\
PEA Ind. 2000 & -.01 & -.08 & .05 \\
PEA Serv. 2000 & -.05 & -.05 & .06 \\
Tx. Analf. 2000 & .00 & .09 & .01 \\
& & $\mathbf{2 0 1 0}$ & \\
\hline & PP & PSDB & PT \\
\hline População 2010 & .17 & -.11 & .03 \\
PEA Agr. 2008 & -.35 & .11 & .08 \\
PEA Ind. 2008 & .24 & -.04 & -.13 \\
PEA Serv. 2008 & .07 & -.08 & .06 \\
Tx. Analf. 2000 & -.56 & .06 & .30 \\
\hline
\end{tabular}

Fonte: Fundação SEADE e TRE-SP.

Obs.: Todas as correlações significativas a 0.01 .

no mostra-se inversamente associado aos contextos industriais $(\mathrm{r}=$ $-0,13)$, sem que se defina uma associação substantiva com contextos de perfil oposto. Essa também foi a trajetória da associação do voto petista para o governo do Estado com municípios segundo a taxa de analfabetismo: a associação inversa, que marca as preferências entre 1990 e 2002 (o aumento da votação segue com a diminuição da taxa), perde força em 2006 e, em 2010, se inverte. As semelhanças com as associações entre variáveis socioeconômicas e o PSDB, que eram observadas em 1990 entre os dois partidos, voltam a ocorrer em 2010, sendo que, em toda a trajetória entre uma eleição e outra, os perfis opostos ficam claramente estabelecidos. Esses dados do final do período sugerem os efeitos da partilha eleitoral entre PT e PSDB mencionada anteriormente. Quanto ao PMDB, o perfil do voto tem características constantes em todo o período até 2006: está associado a contextos menores, em que predomina o perfil agrícola. Na eleição para governo de 2006, a última em que o partido lançou candidato ao governo, destaca-se que as associações entre votações e fatores socioeconômicos são muito frágeis para todos os partidos. 
Na eleição seguinte, em 2010, as associações mantêm-se fracas, mas os dados relativos à votação do PP (com Celso Russomano como candidato) sugerem sua inserção específica no voto conservador em grandes centros, de perfil industrial. Convém lembrar que Russomano, exapresentador de telenoticiários sensacionalistas, é um candidato associado a plataformas sobretudo relacionadas à segurança pública das grandes cidades. Quanto aos outros dois concorrentes, PT e PSDB, suas votações são mais claramente espalhadas no estado, sendo que, no caso do PT, em contextos de perfil mais distante daquele que marcou a sua trajetória inicial de preferências.

No caso do voto conservador especificamente, o perfil bastante definido das bases do PDS associadas em 1982 e 1986 a contextos de menor população e perfil agrícola praticamente se dissipa em 1990, e mesmo a participação de Maluf nas eleições de 1998 e 2002 não recupera a força daquelas correlações, apenas sugere a direção esperada.

No nível municipal, esses perfis de bases partidárias se repetem parcialmente. As associações encontradas são mais fracas, e é possível identificar condições semelhantes para as votações petista e peessedebista, ao nível local, apenas em duas eleições, 1988 e 2004. Para o PMDB e os partidos à direita - PDS, PP, PFL/DEM - há certa constância no perfil dos contextos associados ao voto, caracterizado pela associação inversa com o tamanho dos municípios e com municípios mais industrializados, e associação com cenários com maior taxa de analfabetismo. De toda forma, a fraqueza das associações no âmbito de eleições locais permite afirmar pouco sobre tais preferências (Tabela 10).

As associações encontradas entre as variáveis socioeconômicas e as votações para o legislativo estadual não são significativas em sua grande maioria para todo o período e para os vários partidos. Apenas alguns dados podem ser salientados: novamente o voto petista se destaca, pois, apesar dos baixos valores de r em geral, mostra-se de forma significativa associado a municípios com menor taxa de analfabetismo (em 1990) e de perfil industrial (1994, 1998 e 2002), confirmando a ideia de que esses contextos no estado propiciam a formação de preferências pelo partido até 2002. A partir de 2006 e 2010 os valores encontrados para essa associação são muito baixos, indicando a dispersão das votações. No caso do PMDB, até 2006 a associação com municípios de perfil agrícola acompanha as votações para deputados do partido. Finalmente, no caso do PSDB, os dados (igualmente fracos) indicam certa 
Rachel Meneguello e Fernando Bizzarro Neto

Tabela 10

Correlações r de Pearson entre Votações Partidárias e Fatores

Demográficos e Socioeconômicos nas Eleições

para Prefeito em São Paulo (1988-2008)

\begin{tabular}{|c|c|c|c|c|c|}
\hline \multicolumn{6}{|c|}{1988} \\
\hline & PDS & PFL & PMDB & PSDB & PT \\
\hline População 1990 & .02 & -.06 & -.09 & .08 & .23 \\
\hline PEA Agr. 1990 & .10 & -.03 & .03 & -.04 & -.11 \\
\hline PEA Ind. 1990 & -.06 & -.05 & -.16 & .06 & .21 \\
\hline PEA Serv. 1990 & .01 & .10 & .10 & -.04 & -.15 \\
\hline Tx. Analf. 1991 & .10 & .16 & .15 & -.15 & -.33 \\
\hline \multicolumn{6}{|c|}{1992} \\
\hline & PDS & PFL & PMDB & PSDB & PT \\
\hline População 1990 & .06 & -.05 & -.09 & .0 & .20 \\
\hline PEA Agr. 1990 & .05 & -.05 & .05 & .01 & -.13 \\
\hline PEA Ind. 1990 & -.08 & -.06 & -.12 & .02 & .24 \\
\hline PEA Serv. 1990 & .04 & .11 & .10 & -.01 & -.15 \\
\hline Tx. Analf. 1991 & .08 & .13 & .14 & -.09 & -.33 \\
\hline \multicolumn{6}{|c|}{1996} \\
\hline & PPB & PFL & PMDB & PSDB & PT \\
\hline População 1990 & .09 & -.05 & -.06 & -.04 & .17 \\
\hline PEA Agr. 1990 & -.01 & .03 & .04 & .01 & -.11 \\
\hline PEA Ind. 1990 & -.04 & -.02 & -.00 & -.09 & .20 \\
\hline PEA Serv. 1990 & .03 & .04 & -.03 & .08 & -.13 \\
\hline Tx. Analf. 1991 & -.01 & .15 & .02 & .10 & -.26 \\
\hline \multicolumn{6}{|c|}{2000} \\
\hline & PP & DEM & PMDB & PSDB & PT \\
\hline População 2000 & .02 & -.02 & -.06 & -.03 & .19 \\
\hline PEA Agr. 2000 & .05 & .09 & .09 & .0 & -.18 \\
\hline PEA Ind. 2000 & .01 & -.06 & -.05 & -.07 & .14 \\
\hline lin0PEA Serv. 2000 & -.06 & -.04 & -.04 & .07 & .05 \\
\hline Tx. Analf. 2000 & .05 & .14 & .06 & .06 & -.28 \\
\hline \multicolumn{6}{|c|}{2004} \\
\hline & PP & DEM & PMDB & PSDB & PT \\
\hline População 2000 & .00 & -.05 & -.04 & .03 & .12 \\
\hline PEA Agr. 2000 & .10 & -.00 & .07 & -.02 & -.10 \\
\hline PEA Ind. 2000 & -.01 & -.04 & .00 & -.02 & .09 \\
\hline
\end{tabular}


Tabela 10

Correlações r de Pearson entre Votações Partidárias e Fatores

Demográficos e Socioeconômicos nas Eleições para Prefeito em São Paulo (1988-2008) ～(continuação)

\begin{tabular}{l|r|r|r|r|r}
\hline PEA Serv. 2000 & -.09 & .04 & -.07 & .04 & .01 \\
\hline \multicolumn{7}{l|}{ Tx. Analf. 2000 } & .08 & .10 & .06 & .03 & -.20 \\
\hline \multicolumn{7}{l}{ PP } & \multicolumn{1}{c|}{ DEM } & PMDB & PSDB & \multicolumn{1}{c}{ PT } \\
\hline População 2010 & -.01 & .03 & -.03 & -.01 & .10 \\
PEA Agr. 2008 & .06 & -.03 & .07 & .01 & -.06 \\
PEA Ind. 2008 & .04 & -.08 & -.02 & -.04 & .10 \\
PEA Serv. 2008 & -.09 & .11 & .05 & .04 & -.04 \\
Tx. Analf. 2000 & .01 & .01 & .02 & .20 & -.13 \\
\hline
\end{tabular}

Fonte: Fundação SEADE e TRE-SP.

Obs.: Todas as correlações significativas a 0.01 .

associação com os municípios de perfil industrial nas eleições de 1990, 1994, 2002 e 2006. De toda forma, a descrição dos dados (Tabela 11) não permite qualquer aprofundamento sobre o voto para o legislativo e as variáveis selecionadas.

Os dados de votações por região administrativa necessitam maior detalhamento. Com a exceção dos votos para o PT, que para os três cargos analisados mostram associações significativas e praticamente constantes com contextos de perfil mais industrial e de maior população, há variações importantes que acompanham as características regionais e as formas de estabelecimento das bases partidárias. Assim, é possível encontrar associações entre o voto de partidos conservadores e municípios maiores e com perfil industrial em regiões específicas, provavelmente respondendo à presença de lideranças mais consolidadas. Esses dados, observados ao nível agregado do estado, se perdem, mas analisados regionalmente podem nos dar pistas sobre o movimento das preferências em contextos mais específicos. É o que faz a seção seguinte.

\section{A Trajetória das Votações: Distribuição Regional}

A análise da distribuição dos votos dos principais partidos nas 15 regiões administrativas do estado corrobora nosso argumento quanto à validade da clivagem regional para compreender a consolidação de preferências partidárias e posicionamentos específicos, no caso aqui, o oposicionismo e o governismo. O desenho dessa polarização geografi- 
Rachel Meneguello e Fernando Bizzarro Neto

Tabela 11

Correlações $r$ de Pearson entre Votações Partidárias e Fatores Demográficos e Socioeconômicos nas Eleições para Deputado Estadual em São Paulo

(1988-2008)

\begin{tabular}{|c|c|c|c|c|c|}
\hline \multicolumn{6}{|c|}{1990} \\
\hline & PDS & PFL & PMDB & PSDB & PT \\
\hline População 1990 & $*$ & * & $*$ & $*$ & * \\
\hline PEA Agr. 1990 & * & * & .15 & * & * \\
\hline PEA Ind. 1990 & * & $*$ & -.12 & .15 & * \\
\hline PEA Serv. 1990 & $*$ & * & $*$ & $*$ & * \\
\hline Tx. Analf. 1991 & * & * & .10 & -.25 & -.25 \\
\hline \multicolumn{6}{|c|}{1994} \\
\hline & PDS & PFL & PMDB & PSDB & PT \\
\hline População 1990 & * & * & $*$ & * & .23 \\
\hline PEA Agr. 1990 & $*$ & $*$ & .15 & * & * \\
\hline PEA Ind. 1990 & $*$ & $*$ & -.11 & $*$ & .14 \\
\hline PEA Serv. 1990 & $*$ & $*$ & $*$ & * & * \\
\hline Tx. Analf. 1991 & $*$ & * & $*$ & $*$ & -.23 \\
\hline \multicolumn{6}{|c|}{1998} \\
\hline & PP & PFL & PMDB & PSDB & PT \\
\hline População 1990 & * & * & * & * & .13 \\
\hline PEA Agr. 1990 & $*$ & * & .17 & 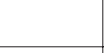 & -12 \\
\hline PEA Ind. 1990 & -.12 & * & $*$ & $*$ & .26 \\
\hline PEA Serv. 1990 & .12 & * & $*$ & $*$ & -.17 \\
\hline Tx. Analf. 1991 & .17 & $*$ & $*$ & * & -.35 \\
\hline \multicolumn{6}{|c|}{2002} \\
\hline & PP & DEM & PMDB & PSDB & PT \\
\hline População 2000 & * & $*$ & $*$ & $*$ & .14 \\
\hline PEA Agr. 2000 & * & * & $*$ & .17 & -.23 \\
\hline PEA Ind. 2000 & $*$ & * & $*$ & -.18 & .23 \\
\hline PEA Serv. 2000 & * & * & $*$ & * & * \\
\hline Tx. Analf. 2000 & * & .19 & * & .18 & -.38 \\
\hline \multicolumn{6}{|c|}{2006} \\
\hline & PP & DEM & РMDB & PSDB & PT \\
\hline População 2000 & * & * & * & * & .12 \\
\hline PEA Agr. 2000 & $*$ & * & .09 & .08 & -.08 \\
\hline PEA Ind. 2000 & * & * & -.11 & -.14 & .09 \\
\hline
\end{tabular}


Tabela 11

Correlações r de Pearson entre Votações Partidárias e Fatores Demográficos e Socioeconômicos nas Eleições para Deputado Estadual em São Paulo (1988-2008) (continuação)

\begin{tabular}{l|r|r|r|r|r}
\hline PEA Serv. 2000 & $*$ & $*$ & $*$ & $*$ & $*$ \\
\hline \multicolumn{7}{l|}{ Tx. Analf. 2000 } & .11 & $*$ & $*$ & .2 & -.10 \\
\hline \multicolumn{7}{l|}{ PP } & DEM & PMDB & PSDB & PT \\
\hline População 2010 & $*$ & $*$ & $*$ & $*$ & $*$ \\
\hline PEA Agr. 2008 & $*$ & $*$ & $*$ & .12 & $*$ \\
\hline PEA Ind. 2008 & $*$ & $*$ & $*$ & -.14 & .09 \\
\hline PEA Serv. 2008 & $*$ & $*$ & $*$ & $*$ & $*$ \\
\hline Tx. Analf. 2000 & $*$ & $*$ & $*$ & .25 & -.10 \\
\hline
\end{tabular}

Fonte: Fundação SEADE e TRE-SP.

* Valores não significativos; as demais correlações são significativas a 0.01 .

camente estabelecida já havia sido apontado por Sadek (1989) na análise da eleição de 1986, quando a tendência oposicionista de novo período marcava suas bases nos grandes centros urbanos, notadamente a região da grande São Paulo, onde o PMDB - então governo - obteve resultados eleitorais reduzidos, comparativamente às regiões do interior.

Ao longo do período 1986-2010, a tendência oposicionista ao governo estadual manteve sua trajetória associada aos maiores centros urbanos, especialmente a capital paulista; por exemplo, as regiões de São Paulo e Santos acolhem um desempenho notável do partido de oposição ao governo a cada eleição, sobretudo do PT. Por outro lado, as regiões de Marília, Presidente Prudente e Bauru, geograficamente distantes da capital e da grande São Paulo, acolhem bons desempenhos eleitorais do PSDB em todo o período que o partido ocupa o governo (Mapa 1). Os dados indicam que, até 2002, a "hegemonia peessedebista" não esteve distribuída homogeneamente, e mostram que em 2010 constituiu-se claramente a partilha política do estado com o PT em todas as regiões, sendo que, apenas na região da capital paulista (RA São Paulo), o partido obteve melhor desempenho que o PSDB para o governo.

No âmbito local, a análise dos dados deve levar em conta a forte fragmentação. Em todo o período, no mínimo 25 partidos obtiveram votações no estado, mas mais da metade obteve votos em no máximo 20 
municípios, ou seja, 3\% do total ${ }^{5}$. Ainda assim, é possível identificar alguns redutos de preferências por partidos específicos, ou seja, regiões em que o partido obteve, ao longo do tempo e a cada eleição, votações superiores à sua média estadual. O mesmo contexto fragmentado repete-se na distribuição regional das votações para o legislativo estadual, no qual, ao longo do período, todos os partidos lançaram candidatos e pulverizaram as preferências.

Nosso interesse nessa seção é apresentar a evolução do desempenho eleitoral regional dos principais partidos, e identificar territórios de preferências mais sólidas, mantidas ao longo do período, diante do fragmentado quadro político paulista. A análise dos dados desenvolve-se com base em três aspectos: o desempenho eleitoral por região e por eleição, que leva em conta as votações partidárias acima da média estadual e ao longo do tempo; a caracterização socioeconômica das regiões administrativas; e a relação centro-periferia, com base na localização das regiões a partir da região da capital paulista. Os dados de cada partido analisado contemplam as votações para primeiro turno das eleições para governo e prefeituras e votações partidárias nas eleições para o legislativo estadual, agregadas por região. Como indicador para definição dos redutos eleitorais, definimos votações partidárias com no mínimo um ponto percentual acima da média estadual, observadas em no mínimo três pleitos seguidos. Consideramos que apresentar tais dados em tabelas (Tabelas 12, 13, 14, 15, 16, 17 e 18) é a melhor estratégia.

\section{O Partido dos Trabalhadores}

A distribuição regional do desempenho eleitoral do PT traz informações importantes. A RA de Santos e a RA de São Paulo são os principais redutos do partido - inclusive bases de sua formação (Meneguello, 1989) - e apresentam em praticamente todas as eleições para todos os cargos (governador, prefeito e deputado estadual) algumas das melhores médias do PT no estado. Em grande medida, esse fenômeno se associa ao mencionado fenômeno das bases do oposicionismo nessas regiões - o partido se consolida ao longo do período como principal candidatura de oposição ao governo do estado - e à persistente, ainda que declinante, associação do voto petista aos contextos mais populosos e com maior atividade industrial. Também com esse perfil e para o voto para o governo, destaca-se ainda a região de Campinas até 2002. Com um perfil socioeconômico mais distinto, de vocação menos industrial, 


\section{Contexto e Competição na Política Paulista}

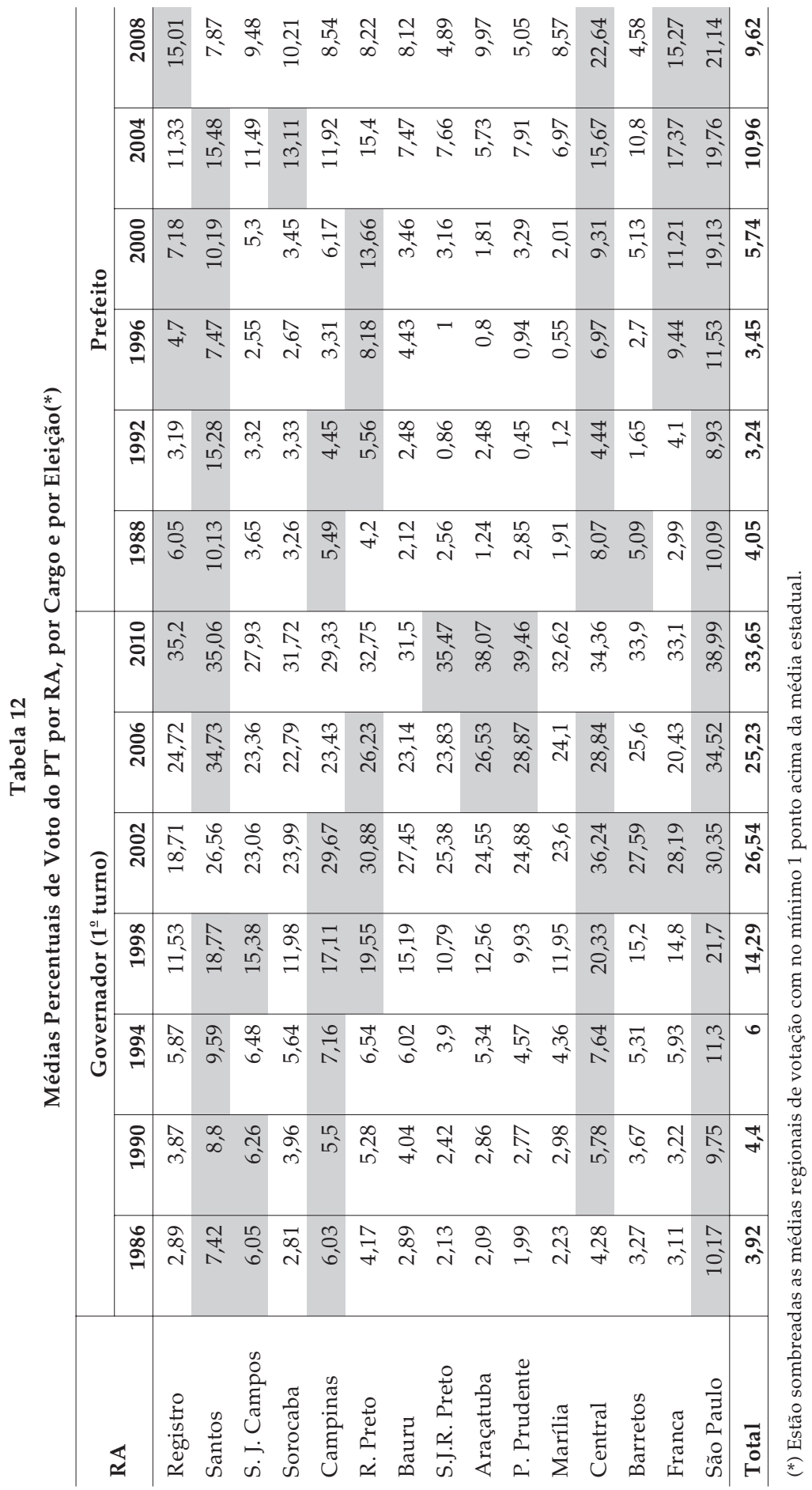







mas geograficamente localizada próxima à capital, destaca-se a região Central, onde encontram-se as cidades de Araraquara e São Carlos. Para o voto para prefeito, soma-se ainda a região de Franca, que adquire maior perfil industrial a partir de 2000, embora seja distante da capital paulista, no norte do estado (Mapa 1). Corroborando as tendências já observadas, as regiões predominantemente agrícolas, compostas por municípios menores e distantes da RA de São Paulo, como Bauru e Marília, mostram resultados eleitorais sempre abaixo da média estadual.

\section{O Partido da Social Democracia Brasileira}

A trajetória eleitoral ascendente do partido tem seu marco inicial nas eleições para o governo de 1994. Nessas eleições, o PSDB obteve médias significativamente maiores que as obtidas entre 1988-1992 em todas as regiões administrativas, dando início a um processo de fortalecimento que se intensifica em 1996 e que atinge seu ponto máximo em 2006. Nessa trajetória, o partido passa da condição inicial de força eleitoral periférica, subdividida do PMDB estadual, para a condição de partido mais votado do estado, obtendo médias superiores a $25 \%$ dos votos dos municípios em praticamente todas as eleições do período 1996-2010. Os principais terrenos peessedebistas são as regiões de São José dos Campos, Sorocaba, Bauru e Marília, que mostram preferências acima da média estadual tanto para as votações para o governo quanto para a prefeitura. No caso de São Josédos Campos, mostra também preferências constantes no tempo para o legislativo estadual. No âmbito das eleições legislativas, emergem como redutos a partir de 2002 as regiões de Bauru, Registro e Franca. No âmbito local, destacam-se ainda as regiões de Ribeirão Preto, Araçatuba e Presidente Prudente.

Cabe destacar que todas as regiões em destaque pelo bom desempenho continuado acompanham o padrão de localização do "governismo" mencionado anteriormente, distantes da capital paulista, com perfil comparativamente menos urbanizado e de vocação menos industrial. Nas regiões de São Paulo e Santos, o fenômeno já mencionado do oposicionismo consolidado fez com que, exceto nas eleições de 1994 em Santos - quando o candidato ao governo do PSDB foi Mário Covas, liderança com ligações históricas com a região, e em 2004, quando o candidato a prefeito em São Paulo foi José Serra - o partido tenha obtido ali alguns de seus piores resultados médios no período. 


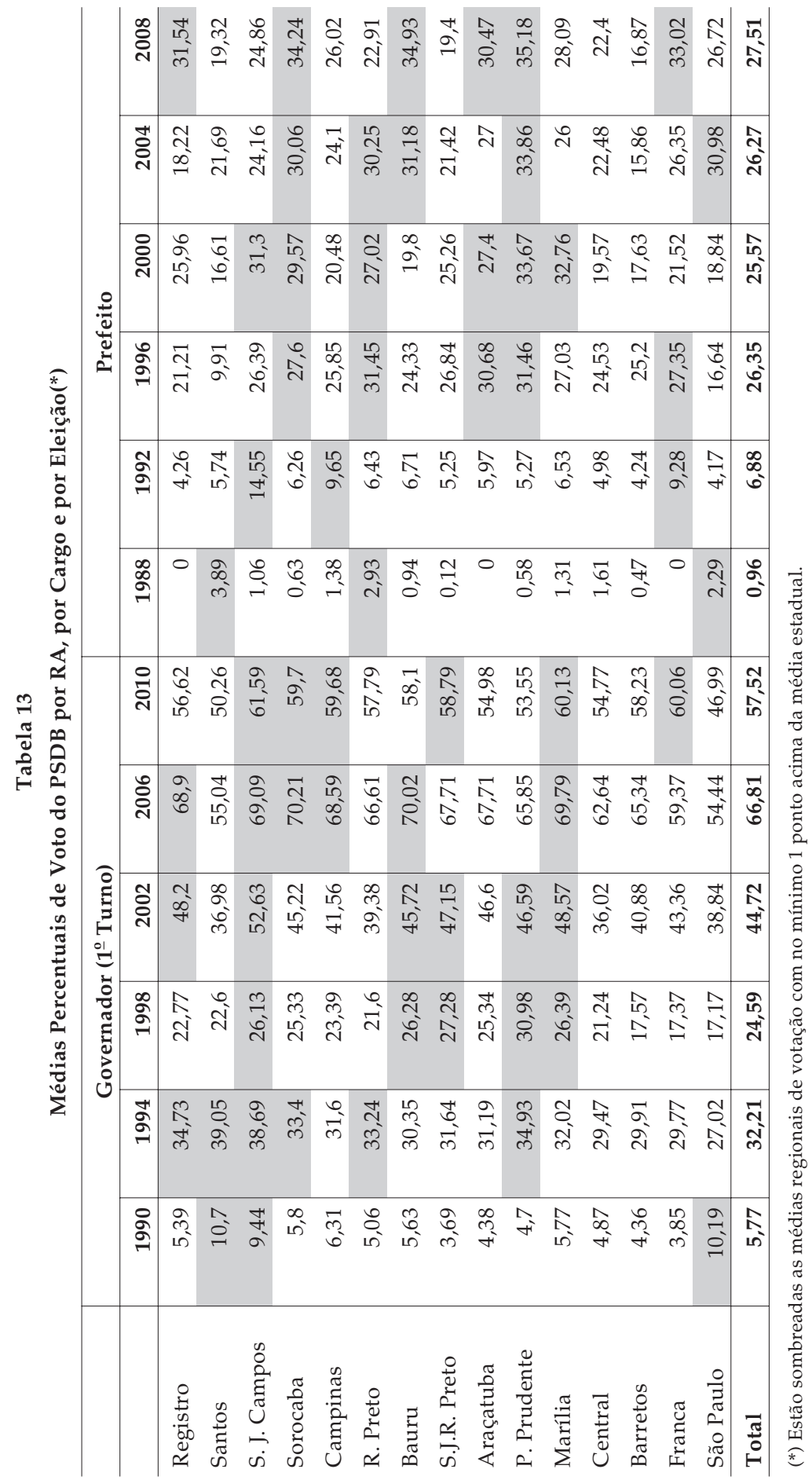




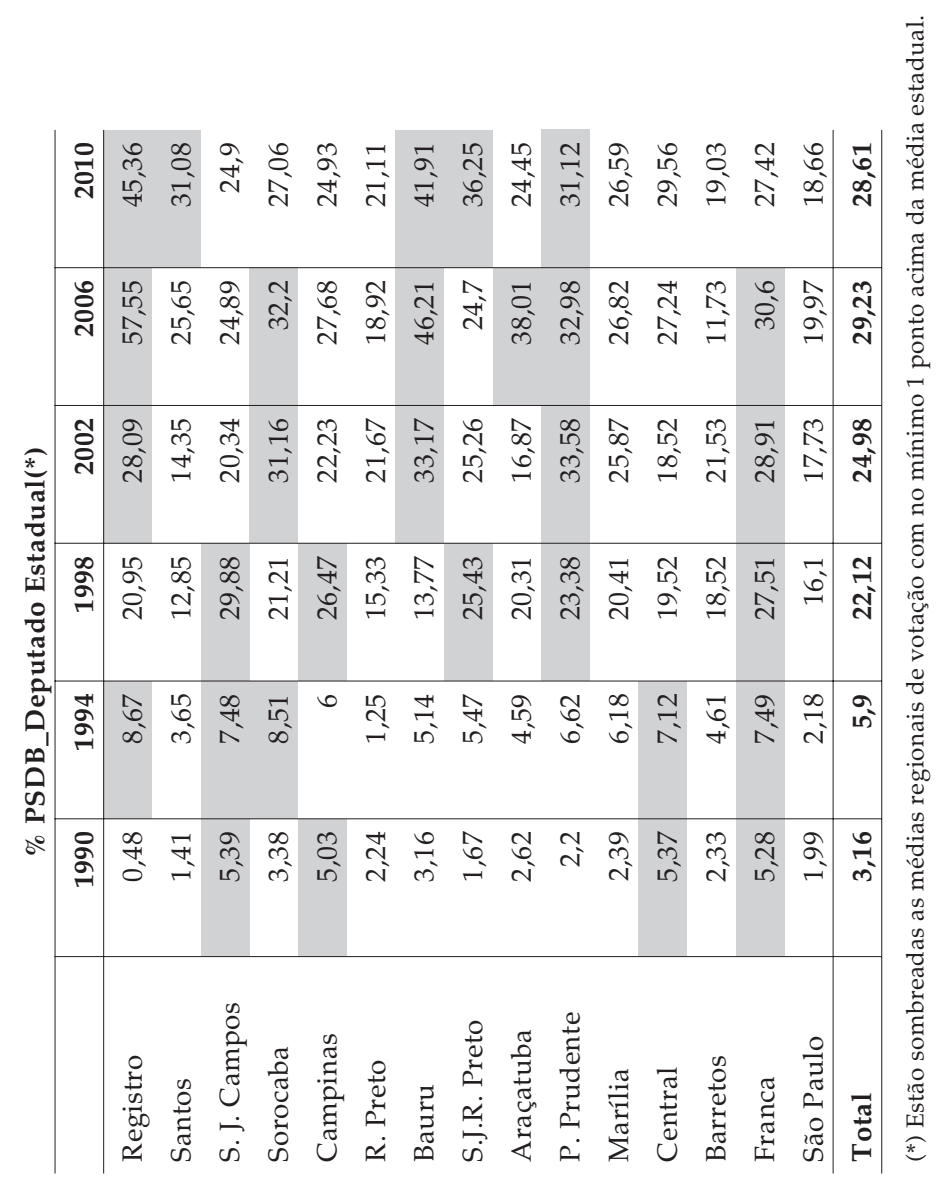




\section{O Partido Democrático Social/Partido Progresssista}

Os dados mostram que a importância que o PDS teve na divisão da política estadual com o PMDB no início da transição democrática, com a eleição de 1982, dissipou-se no decorrer do período pós-85. Nas eleições para o governo em que Paulo Maluf, sua principal liderança, figurou como candidato (1986, 1990, 1998 e 2002), o partido teve até 1998 desempenho considerável em todas regiões no 1o turno eleitoral, mas especialmente nas regiões de Registro, Santos, São José dos Campos, Sorocaba, Presidente Prudente e Araçatuba, que mantêm no tempo boas votações; no entanto, podem ser considerados redutos apenas as regiões de Presidente Prudente e Santos. As mudanças de nomenclatura para a legenda não afetaram seu desempenho - ao contrário, foram mecanismos utilizados para garantir a sobrevivência partidária (Almeida, 2004) -, mas, de fato, sua força declina a partir de 2002, em função da ascensão do PSDB, da partilha política com o PT e do declínio eleitoral de Paulo Maluf.

No nível local, já desde o inicio do periodo democrático o declínio da legenda pode ser observado, e apenas as regiões de São José do Rio Preto, Ribeirão Preto e Barretos podem ser consideradas redutos do partido. Quanto às votações para deputado estadual, será na eleição de 1998 que o partido reencontrará espaço no terreno fragmentado, definindo redutos nas RAs de São José do Rio Preto e Araçatuba, até2006, e em Presidente Prudente, apenas até 1998.

\section{O Partido Trabalhista Brasileiro}

Assim como para o PDS/PP, a distribuição regional mostra bases de preferências consolidadas no tempo apenas em algumas regiões. As variações do voto entre as eleições são intensas, de forma que bons resultados regionais obtidos pelo partido em um determinado período não se consolidam na direção de constituir uma tendência estável. As candidaturas para o governo ocorreram em apenas duas eleições muito distantes, 1986 e 2002, levando o partido a figurar em algumas coligações, ou nem isso (ver Tabela 2). No âmbito local, três regiões sustentam preferências pelo partido desde 2000, Registro, Ribeirão Preto e Presidente Prudente, todas com perfil predominante agrícola e distantes da capital paulista (Mapa 1). No início do período estudado, Barretos e São Paulo eram regiões com desempenho importante, mas que se perdem no tempo. No voto para deputado estadual, apesar dos relativa- 


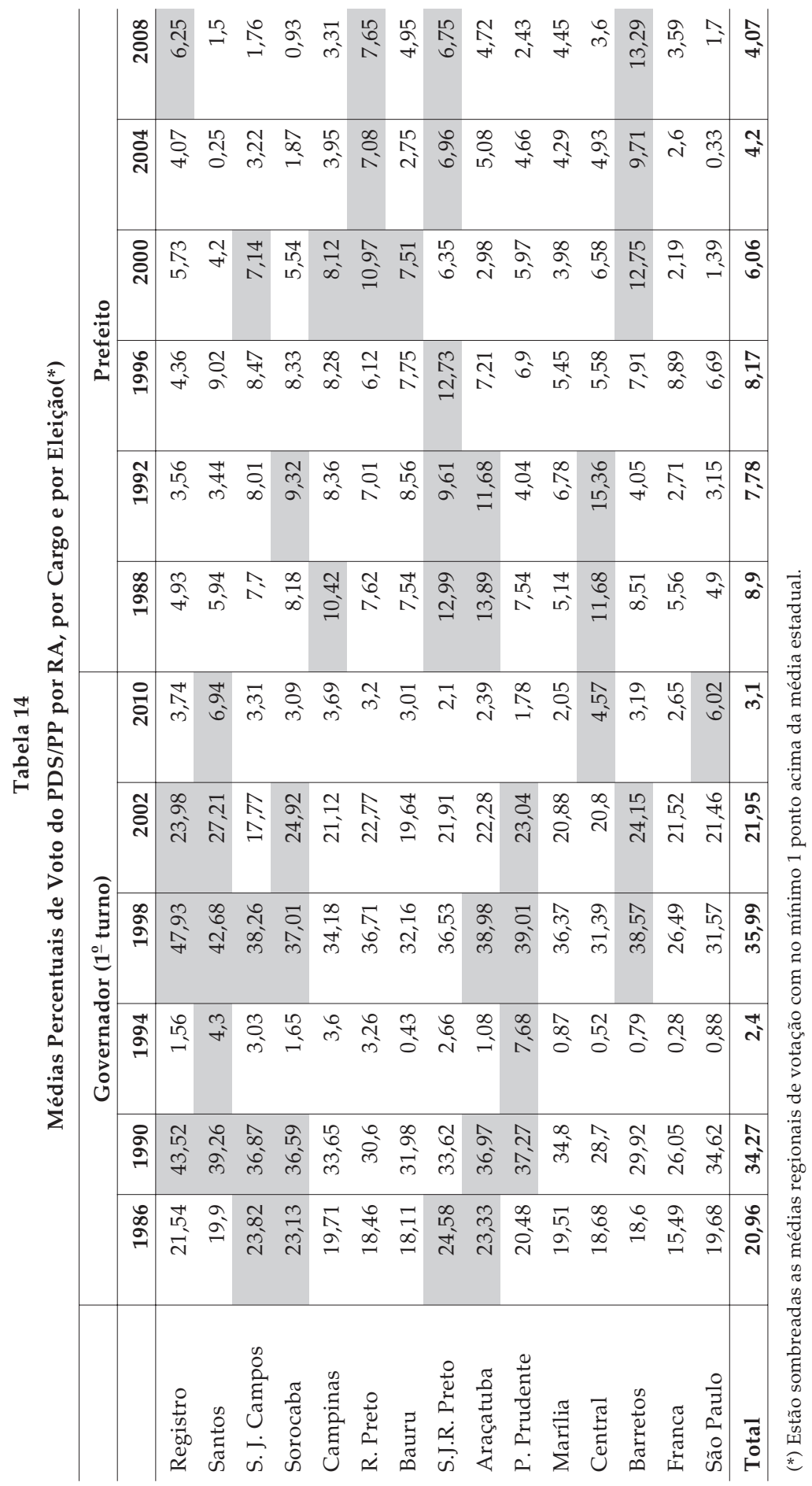


Rachel Meneguello e Fernando Bizzarro Neto

\% PDS/PP_Deputado Estadual(*)

\begin{tabular}{l|r|r|r|r|r|r|r}
\hline & $\mathbf{1 9 8 6}$ & $\mathbf{1 9 9 0}$ & $\mathbf{1 9 9 4}$ & $\mathbf{1 9 9 8}$ & $\mathbf{2 0 0 2}$ & $\mathbf{2 0 0 6}$ & $\mathbf{2 0 1 0}$ \\
\hline Registro & 5 & 1,69 & 1,56 & 9,97 & 3,22 & 0,64 & 1,63 \\
Santos & 3,53 & 2,01 & $\mathbf{4} 3$ & 11,92 & 6,31 & 1,73 & 3,04 \\
S. J. Campos & 5,95 & 5,91 & $\mathbf{3}, 03$ & 18,84 & 4,27 & 0,94 & 1,09 \\
Sorocaba & 8,14 & 2,89 & 1,65 & 14,93 & 6,28 & 2,88 & 2,53 \\
Campinas & 7,47 & 3,66 & 3,6 & 9,85 & 5,81 & 2,41 & 1,51 \\
R. Preto & 5,83 & 0,56 & 3,26 & 7,39 & 3,08 & 1,96 & 0,92 \\
Bauru & 4,83 & 2,05 & 0,43 & 16,66 & 3,45 & 0,94 & 2,23 \\
S.J.R. Preto & 9,33 & 3,43 & 2,66 & 17,00 & 7,79 & 5,06 & 1,93 \\
Araçatuba & 10,08 & 3,09 & 1,08 & 21,53 & 9,29 & 5,54 & 1,58 \\
P. Prudente & 7,63 & 8,55 & 7,68 & 21,57 & 2,8 & 2,97 & 0,8 \\
Marília & 8,9 & 3,3 & 0,87 & 16,28 & 3,77 & 1,11 & 3,28 \\
Central & 6,29 & 2,72 & 0,52 & 6,51 & 2,06 & 2,37 & 1,61 \\
Barretos & 7,22 & 1,36 & 0,79 & 5,44 & 4,26 & 1,35 & 1,02 \\
Franca & 5,68 & 0,44 & 0,28 & 3,77 & 6,75 & 2,29 & 1,68 \\
São Paulo & 7,95 & 2,16 & 0,88 & 12,98 & 5,1 & 1,68 & 1,28 \\
\hline Total & $\mathbf{7 , 5 7}$ & $\mathbf{3 , 4}$ & $\mathbf{2 , 4}$ & $\mathbf{1 4 , 3 9}$ & $\mathbf{5 , 3 9}$ & $\mathbf{2 , 6 9}$ & $\mathbf{1 , 7 9}$ \\
\hline
\end{tabular}

(*) Estão sombreadas as médias regionais de votação com no mínimo 1 ponto acima da média estadual.

mente altos resultados na $R A$ de Araçatuba desde 1998, nenhuma região configura um reduto mais consolidado. Como já mencionamos, o partido nunca teve bases fortemente constituídas no estado, mesmo no período em que a sigla vigia entre 1945 e 1964. Além da vitória de Jânio Quadros para a prefeitura da capital, em 1985, as únicas eleições em que o partido lançou candidato ao governo foi em 1986, com o empresário Antônio Ermírio de Moraes, quando obteve quase $24 \%$ dos votos, e mais tarde, em 2002, com Antônio Cabrera, ex-ministro da Agricultura do governo Collor, com bases na região de São José do Rio Preto. Os ínfimos 1,02\% de votos obtidos no estado naquela eleição traduzem a fragilidade das bases do partido.

\section{O Partido da Frente Liberal/ Democratas}

O principal reduto do PFL no período é a RA de Registro, a mais pobre do estado, localizada ao sul (Mapa 1). Ainda que o partido não tenha lançado nenhum candidato ao governo do Estado, essa região mantém preferências principalmente nas eleições para a prefeitura, acompanhada parcialmente por bons resultados nas eleições para seus candi- 





datos à Assembleia Legislativa. As principais votações estão sistematicamente localizadas no interior menos urbanizado e menos industrializado do Estado. No nível local, as regiões são São José do Rio Preto e Araçatuba a partir de 1996, e Presidente Prudente e Marília, já desde o início do período. No voto para o legislativo, apenas na região de Sorocaba o partido obtém boas votações consecutivas.

\section{O Partido do Movimento Democrático Brasileiro}

O PMDB merece uma análise mais detalhada, afinal, estruturou no estado o voto de oposição ao regime militar como MDB, adquiriu hegemonia eleitoral desde o início do período democrático por meio do forte espalhamento de suas preferências, e com a ampliação do quadro partidário entrou em uma aguda trajetória de queda nas eleições majoritárias e proporcionais.

O realinhamento eleitoral produzido a partir de 1974, marcado pelo fortalecimento da oposição ao regime militar, teve em São Paulo um de seus principais vetores, criando as condições para que o PMDB predominasse sobre a política paulista durante toda a década de 1980 (Lamounier, 1980). No período inicial da redemocratização, o partido elegeu todos os governadores e senadores do Estado, além das maiores bancadas na Assembleia Legislativa e na Câmara dos Deputados. O auge desse predomínio foram as eleições de 1986 quando, impulsionado pelo sucesso do Plano Cruzado e pela retomada da democracia, o PMDB obteve vitória eleitoral em todo o país (Sadek, 1989; Melhem, 1998). Contudo, a partir de 1990, o desempenho eleitoral do partido iniciou um agudo declínio: no âmbito legislativo, de 28 deputados federais e 27 deputados estaduais eleitos em 1986, o partido chega em 2010 com apenas 1 deputado federal e 4 deputados estaduais eleitos, e conforme o Gráfico 2 mostrou anteriormente, de $45 \%$ de prefeitos eleitos em 1992, o partido caiu em 2008 para apenas $11 \%$.

Além do declínio, os dados sobre a votação do partido no período também apontam a crescente concentração da votação nos menores municípios do interior paulista. O fenômeno da "interiorização" do partido já observado desde 1986 por Sadek (1989) consistia no seu enfraquecimento nos maiores municípios e no aumento da participação do volumoso conjunto dos menores municípios na composição do total de votos obtidos, um movimento associado ao governismo incorporado pelo partido em 1986 e 1990. Tal tendência eleitoral contrariava os pa- 


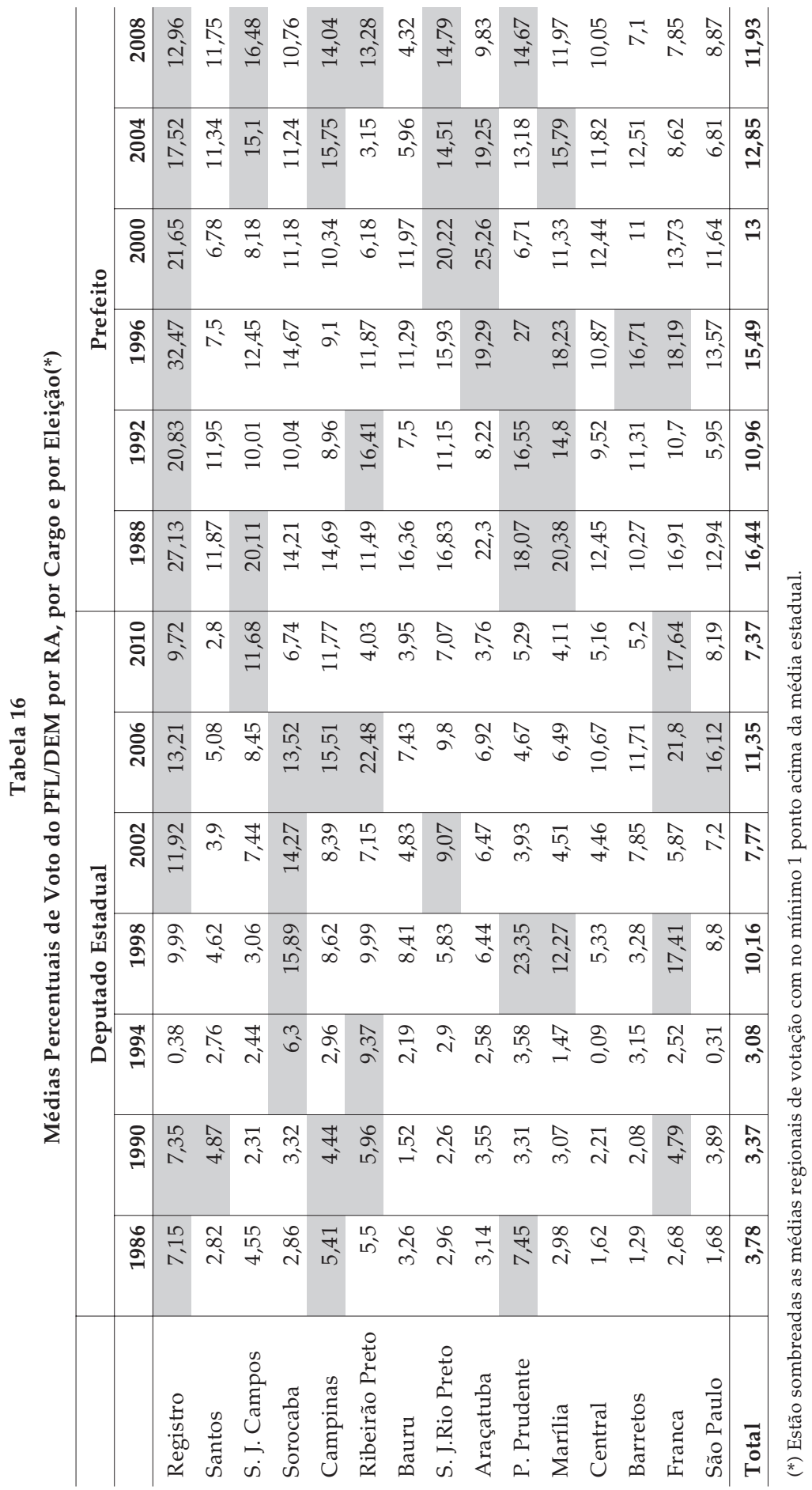


drões de votação oposicionista da década de 1970 encontrados por Lamounier (1980), nos quais se destacava a grande vinculação entre o eleitorado de periferia nas grandes cidades com o MDB. A Tabela 17 mostra a presença dessa relação invertida para os três cargos, sobretudo até 1998. Na década de 2000, o declínio generalizado levou a que a distribuição das votações fosse semelhante nos três conjuntos distintos de municípios, mas apenas naqueles com menos de 20 mil habitantes o partido obteve médias regionais de votação acima da média estadual nas eleições para governador e prefeito.

A distribuição das votações por regiões mostra uma aguda queda das preferências eleitorais em todo o estado, mas mostra também a notável manutenção de três redutos, as regiões de Barretos, São José do Rio Preto e Franca, que obtiveram votações consecutivas acima da média estadual em todo o período em quase todas as eleições para os três cargos analisados, governador, prefeito e deputado estadual. Apenas no nível local, somam-se ainda as regiões de Marília e Bauru. A concentração das melhores médias de votação do partido ocorre nas regiões mais distantes da capital, que consolidaram suas bases durante o processo de interiorização do voto governista dos anos 1980 e início dos anos 1990 (ver Mapa 1). É notável que o partido não tenha tido desempenho relevante na região de São Paulo, em nenhuma eleição para os três cargos analisados.

Finalmente, cabe apontar que, assim como o DEM, o PMDB se tornou ao longo do período um partido de "vocação local", um fenômeno caracterizado pela maior resistência das médias de votos para prefeito frente à tendência geral de declínio notadamente observada nas votações para os candidatos a governador, e que culminou com o não lançamento de candidatura ao governo nas eleições de 2010. Em grande medida, essa vocação local está relacionada ao "quercismo", fenômeno político de bases especialmente municipais desenvolvido no interior do estado (Melhem, 1998).

No voto para o legislativo, fica reiterada a importância das regiões de Franca e Barretos, e adicionam-se a região Central e, a partir de 2002, Ribeirão Preto. A região de Bauru, que tem um desempenho significativo nas eleições para prefeito em todo o período, para o legislativo estadual teve um declínio importante desde a eleição de 2002. 










\% PMDB_Dep. Estadual(*)

\begin{tabular}{l|r|r|r|r|r|r|r}
\hline & $\mathbf{1 9 8 6}$ & $\mathbf{1 9 9 0}$ & $\mathbf{1 9 9 4}$ & $\mathbf{1 9 9 8}$ & $\mathbf{2 0 0 2}$ & $\mathbf{2 0 0 6}$ & $\mathbf{2 0 1 0}$ \\
\hline Registro & 14,49 & $\mathbf{7 , 1 6}$ & 13,2 & 20,81 & 10,68 & 3,28 & 3,85 \\
Santos & 12,52 & 4,78 & 11,95 & 13,87 & 4,07 & 7,41 & 8,92 \\
S. J. Campos & 26,33 & $\mathbf{6}, 46$ & 8,85 & $\mathbf{6 , 1 6}$ & 2,4 & 2,79 & 3,8 \\
Sorocaba & 20,49 & 9,98 & 16,24 & 11,15 & 5,24 & 3,17 & 4,11 \\
Campinas & 21,94 & 7,79 & 11,88 & 10,82 & 6,85 & 4,55 & 4,74 \\
R. Preto & 25,74 & 4,63 & 8,02 & 9,67 & 11,51 & 8,42 & 19,3 \\
Bauru & 24,41 & 12,78 & 18,48 & 17,55 & 6,05 & 1,45 & 2,38 \\
S.J.R. Preto & 28,79 & 12,27 & 12,46 & 12,29 & 3,03 & 2,72 & 10,82 \\
Araçatuba & 19,6 & 7,86 & 10,81 & 3,63 & 2,33 & 3,36 & 4,96 \\
P. Prudente & 24,21 & 12,38 & 19,5 & 7,34 & 4,99 & 9,74 & 4,35 \\
Marília & 25,42 & 13,64 & 16,86 & 10,55 & 4,79 & 2,65 & 1,25 \\
Central & 26,41 & 15,91 & 27,96 & 33,18 & 8,07 & 5,33 & 9,85 \\
Barretos & 32,29 & 16,08 & 32,14 & 21,94 & 3,66 & 17,92 & 25,55 \\
Franca & 27,03 & 11,87 & 10,31 & 11,6 & 9,77 & 11,29 & 10,09 \\
São Paulo & 10,78 & 7,1 & 14,74 & 8,54 & 3,23 & 4,37 & 5,3 \\
\hline Total & $\mathbf{2 3 , 3 4}$ & $\mathbf{1 0 , 2 8}$ & $\mathbf{1 4 , 8 9}$ & $\mathbf{1 1 , 7 5}$ & $\mathbf{5 , 2 1}$ & $\mathbf{4 , 8 3}$ & $\mathbf{6 , 7 2}$ \\
\hline
\end{tabular}

(*) Estão sombreadas as médias regionais de votação com no mínimo 1 ponto acima da média estadual.

Dentre as várias interpretações do declínio do voto peemedebista no estado, a fundação do PSDB tem papel óbvio no conjunto de explicações. A constituição de uma nova legenda localizada praticamente no mesmo espaço ideológico a partir da migração de antigas lideranças do partido e a perda do controle da máquina estadual a partir de 1994 foram decisivos para a perda da capacidade eleitoral do PMDB, diante de um quadro altamente competitivo.

\section{ALGUMAS CONCLUSÕES}

Um de nossos objetivos neste texto foi resgatar o enfoque contextual para entender a trajetória das votações no estado de São Paulo no período democrático recente. Por um lado, fomos estimulados pela ideia de que os parâmetros da racionalidade, que têm vigorado nas explicações do comportamento eleitoral, marginalizaram de forma significativa e indevida as abordagens que reconhecem o impacto dos diferentes níveis da realidade social sobre o comportamento político. Por outro lado, quisemos reagir ao senso geral quando afirma que os avanços 
da sociedade contemporânea, os efeitos das transformações culturais e o impacto dos múltiplos agentes de comunicação e socialização, enfim, as mudanças da política, superam a hipótese dos determinantes contextuais.

Nossos dados sugerem que a política paulista se estabelece em territórios específicos. A manutenção dos espaços onde o oposicionismo e o governismo fundaram suas bases desde o início do período analisado é um ponto de destaque. A distribuição das preferências segundo as regiões administrativas mostrou que a dinâmica centro-periferia atua no estado, e coloca o voto dado aos partidos no governo e aos partidos conservadores nas regiões mais distantes da região da capital paulista, com características socioeconômicas e demográficas afins. Na região de São Paulo, onde está a capital, e em Santos, região litorânea, ambas altamente urbanizadas, tem presença maior o voto de oposição ao governo e, notadamente, o voto petista.

Além disso, identificamos contextos de votação à esquerda e à direita do espectro partidário no estado, corroborando a ideia de que, nos agregados urbanos e suas distinções internas, é possível identificar características socioeconômicas que beneficiam a presença de tendências específicas. Nesse aspecto, encontramos que contextos caracterizados por municípios menos populosos, com maior taxa de analfabetismo e uma ocupação da PEA associada predominantemente à agricultura, beneficiam o desempenho de partidos conservadores, como o PDS/PP, PTB e PFL/DEM, além de acolher o voto governista. Também encontramos a manutenção parcial do perfil do voto petista observado no estado desde sua fundação, localizado em contextos mais urbanizados e industriais e com menor taxa de analfabetismo, uma tendência que se transforma com o "espalhamento" das preferências a partir de 2006.

Com relação à evolução da competição no estado, mostramos que a partir de 1994 a política paulista se orienta pela dinâmica que estrutura a política nacional, e o terreno de preferências, ao final do período, constitui uma clara partilha entre o PSDB e o PT.

Finalmente, sobre as bases dos principais partidos no estado: tanto os dados de associações apresentadas para as votações de um mesmo partido entre eleições, quanto a distribuição das votações nas regiões administrativas, permitem apontar que as agremiações estudadas estru- 
turam preferências e organizam a escolha eleitoral, em uma dinâmica resistente ao cenário partidário fragmentado paulista.

(Recebido para publicação em dezembro de 2011)

(Reapresentado em fevereiro de 2012)

(Aprovado para publicação em março de 2012)

\section{NOTAS}

1. A definição arbitrária dos cargos analisados, com a exclusão das votações para deputado federal e senador, responde à escolha por aprofundar neste artigo a análise de dados de nível local; sustentamos que, ao lado da compreensão da competição para o cargo de governador, as votações para prefeito e deputado estadual podem nos dar esse panorama.

2. Os dados de votação por município no Estado de São Paulo disponibilizados pelo TRE-SP e pela Fundação SEADE para a Assembleia Legislativa nas eleições de 1986, 1990 e 1994 apenas incluem as dez maiores votações por municípios. Essa limitação não prejudicou a análise dos partidos selecionados.

3. Conhecemos o debate sobre a pertinência ou não da consideração de níveis de significância quando os dados analisados não são amostrais, como é o caso dos dados utilizados neste artigo. Optamos por considerá-los nas várias tabelas apresentadas. Para os dois lados desse debate, ver Cowger (1984) e Rubin (1985).

4. Estamos cientes das mudanças na composição da força de trabalho e do impacto dos processos de reestruturação produtiva ocorridos nas últimas décadas sobre o perfil da PEA (ver Araújo, 2001; Matteo e Tapia, 2002). As definições de PEA agrícola, industrial e de serviços estabelecidas ao longo do período não estão explicitadas aqui, mas recorremos a esses fatores para embasar nosso argumento de que posicionamentos e preferências político-partidárias são fenomenos em parte associados aos processos sociais neles refletidos.

5. Em 1988, 25 partidos lançaram candidatos a prefeito, 15 obtiveram votos em no máximo 20 municípios (3\%); em 1992, de 25 partidos, 11 obtiveram votos em no máximo 20 municípios; em 1996, de 29 partidos, 16 obtiveram votos em no máximo 20 municípios; em 2000, dos 30 partidos, 18 obtiveram votos em no máximo 20 municípios; e em 2004 e 2008, de 27 partidos, 13 obtiveram votos em apenas até 3\% dos municípios. 


\section{REFERÊNCIAS BIBLIOGRÁFICAS}

AGNEW, John. (1996), “Mapping Politics: How Context Counts in Electoral Geography". Political Geography, vol. 15, no 2, pp. 129-146, 1996.

ARAUJO, Maria de Fátima I. (2001), “Reestruturação Produtiva e Transformações Econômicas: Região Metropolitana de São Paulo". São Paulo em Perspectiva, vol. 15, no 1, pp. 20-30.

AVELAR, Lúcia, WALTER, Maria Inês M. T. (2008), “Lentas Mudanças: O Voto e a Política Tradicional". Opinião Pública, vol. 14, no 1, pp. 96-122.

ALMEIDA, Ludmila C. (2004), PPB: Origem e Trajetória de um Partido de Direita. Dissertação de Mestrado, Programa de Pós-Graduação em Ciência Política na FFLCH/USP, São Paulo.

BEST, R. E. (2011), “The Declining Electoral Relevance of Traditional Cleavage Groups". European Political Science Review, vol. 3, no 2, pp. 279-300.

BRAGA, Maria do Socorro S. e KINZO, Maria D’ Alva G. (2007), “Sistema Eleitoral, Competição Partidária e Representação Parlamentar nos Legislativos Estaduais", in M. S. Braga e M. D. G. Kinzo (orgs.), Eleitores e Representação Partidária no Brasil. São Paulo, Associação Editorial Humanitas, pp.159-178.

COWGER, Charles. (1984), “Statistical Significance Tests: Scientific Ritualism or Scientific Method?". Social Science Review, vol. 58, no 3, pp. 358-372.

DALTON, Russell J. e ANDERSON, Christopher J. (2011), “Citizens, Context and Choi$\mathrm{ce}^{\prime \prime}$, in R. J. Dalton e C. J. Anderson (orgs.), Citizens, Context and Choice. How Context Shapes Citizens' Electoral Choices. Oxford, Oxford University Press.

EVANS, Geoffrey (org.). (1999), The End of Class Politics? Class Voting in Comparative Context. Oxford, Oxford University Press.

FARIA, Vilmar. (1975), “As Eleições de 1974 no Estado de São Paulo: Uma Análise das Variações Inter-regionais", in B. Lamounier e F. H. Cardoso (orgs.), Os Partidos e as Eleições no Brasil. São Paulo, Cebrap/Paz e Terra, pp. 205-242.

FERREIRA, Denise P., BATISTA, Carlos M. e STABILE, Max. (2008), “A Evolução do Sistema Partidário Brasileiro: Número de Partidos e Votação no Plano Subnacional 1982-2006". Opinião Pública, vol. 14, no 2, pp. 432-453.

FIGUEIREDO, Marcus e JORGE, Vladimyr L. (1997), “São Paulo: Dinâmica e Formato do Sistema Partidário", in O. B. de Lima Jr. (org.), O Sistema Partidário Brasileiro: Diversidades e Tendências, 1982-94. Rio de Janeiro, Editora da FGV, pp. 267-299.

GONÇALVES, André R. (1998), Estudo da Organização Partidária Local em São Paulo: Caracterização das Bases Sociais Partidárias. Trabalho elaborado para a disciplina ME-872 - Estatística Aplicada, IMECC/UNICAMP (mimeo).

INGLEHART, Ronald. (1997), Modernization and Postmodernization: Cultural, Economic and Political Change in 43 Societies. Princeton, Princeton University Press.

JOHNSTON, Ron e PATTIE, Charles J. (2006), Putting Voters in their Place: Geography and Elections in Great Britain. Oxford, Oxford University Press. 


\section{Contexto e Competição na Política Paulista}

KARVONEN, Laurie e KUHNLE, Stein (orgs.). (2005), Party Systems and Voter Alignments Revisited. London/New York, Routledge.

KERBAUY, Maria Tereza. (2000), A Morte dos Coronéis: Política Interiorana e Poder Local. Araraquara/São Paulo, FCL/Unesp/Cultura Acadêmica.

LAMOUNIER, Bolivar. (1980), “Comportamento Eleitoral em São Paulo: Passado e Presente", in B. Lamounier (org.), Voto de Desconfiança: Eleições e Mudança Política no Brasil: 1970-1978. São Paulo, Vozes/Cebrap, pp.15-80.

LIJPHART, Arend. (1984), Democracies: Patterns of Majoritarian and Consensus Government in Twenty-One Countries. New Haven, Yale University Press.

LIMA Jr., Olavo Brasil. (1993), Democracia e Instituições Políticas no Brasil dos Anos 80. São Paulo, Edições Loyola.

LIPSET, Seymour M. (2005), “Cleavages, Parties and Democracy”, in L. Karvonen e S. Kuhnle (orgs.), Party Systems and Voter Alignments Revisited. London/New York, Routledge, pp. 3-9.

e ROKKAN, Stein (orgs.). (1967), Party Systems and Voter Alignments: Cross-National Perspectives. New York, The Free Press.

MAIR, Peter. (2005), "The Freezing Hypothesis: An Evaluation", in L. Karvonen e S. Kuhnle (orgs.), Party Systems and Voter Alignments Revisited. London/New York, Routledge, pp. 26-44.

MATTEO, Miguel e TAPIA, Jorge Ruben B. (2002), “Características da Indústria Paulista nos Anos 90: Em Direção a uma City Region?". Revista de Sociologia Política, no 18, pp.73-93.

MELHEM, Célia S. (1998), Política de Botinas Amarelas: O MDB-PMDB Paulista de 1965 a 1988. São Paulo, Hucitec/USP.

MENEGUELLO, Rachel. (1989), PT: A Formação de um Partido, 1979-1982. São Paulo, Paz e Terra.

. (2011), “Las Elecciones de 2010 y los Rumbos del Sistema de Partidos Brasileño. Política Nacional, Fragmentación y Lógica de Coaliciones", in M. A. Sáez e M. L. Tagina (eds.), América Latina: Política y Elecciones del Bicentenario (2009-2010). Madrid, Centro de Estudios Politicos y Constitucionales, pp. 449-497.

e ALVES, Ricardo M. (1986), “Tendências Eleitorais em São Paulo (1974-1985)”, in B. Lamounier (org.), 1985: O Voto em São Paulo, História Eleitoral. São Paulo, Idesp, pp. 90-123.

REIS, Fábio W. e CASTRO, Mônica M. Machado. (1992), “Regiões, Classe e Ideologia no Processo Eleitoral Brasileiro". Lua Nova, no 26, pp. 81-131.

RUBIN, Allen. (1985), “Significance Testing with Population Data”. Social Science Review, vol. 59, no 3, pp. 588-606.

SADEK, Maria Tereza. (1989), “A Interiorização do PMDB nas Eleições de 1986 em São Paulo”, in M. T. Sadek (org.), Eleições 1986: História Eleitoral do Brasil. São Paulo, IDESP/Vértice.

SECRETARIA DE PLANEJAMENTO E DESENVOLVIMENTO REGIONAL DE SÃO PAULO. (2010), Enfoque Regional, maio. 


\section{Rachel Meneguello e Fernando Bizzarro Neto}

SIMÃO, Aziz. (1956), “O Voto Operário em São Paulo”. Revista Brasileira de Estudos Políticos, vol. I, no 1, pp. 130-141.

TAYLOR, Peter J. e JOHNSTON, Ron J. (1979), The Geography of Elections. London, Penguin Books. 


\section{Lista de Siglas dos Partidos Políticos}

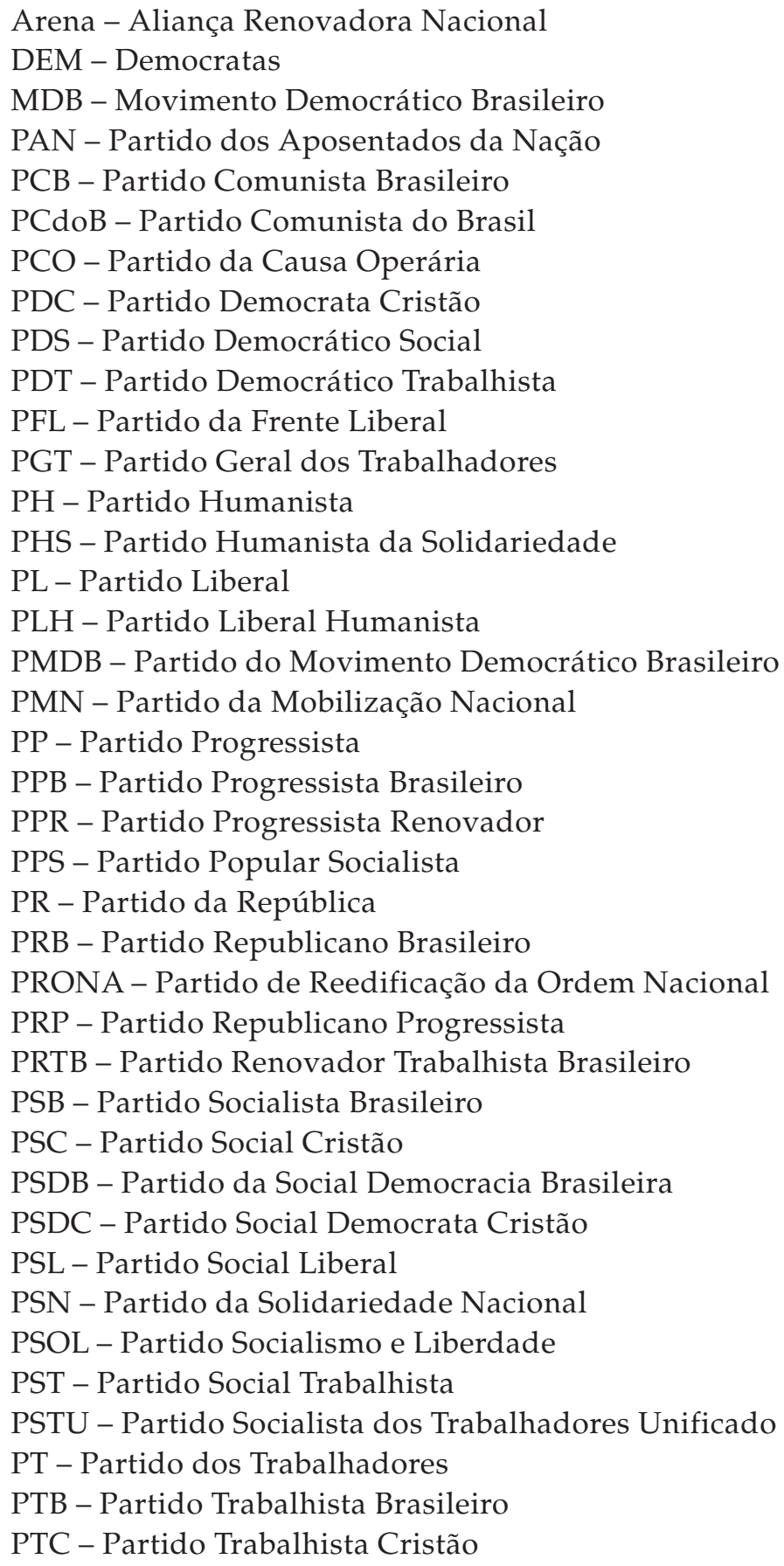


Rachel Meneguello e Fernando Bizzarro Neto

PTdoB - Partido Trabalhista do Brasil

PTN - Partido Trabalhista Nacional

PTR - Partido Trabalhista Reformador

PV - Partido Verde 


\section{ABSTRACT \\ Context and Competition in São Paulo Politics}

This article analyzes the changes in local politics and in political parties' electoral bases in São Paulo since 1985. The study refocuses on the premises of the contextual approach and electoral geography to show that São Paulo politics displays specific territories, and that both socioeconomic structural factors and the dynamics of relations between the center and the periphery act to shape electoral preferences. As for competition in the State, the study shows that since 1994, politics in São Paulo has been oriented by the dynamics of Brazilian national politics, grounded in the bipartisan dispute between the Workers' Party (PT) and the Brazilian Social Democratic Party (PSDB). Finally, concerning the organization of the main political parties' electoral bases, the study indicates that the parties that were already organized at the beginning of the period, namely PT, PSDB, PMDB, PDS/PP, PTB, and PFL/DEM, have bases that are reasonably well rooted among the voter constituency and that they organize choices according to a dynamic that resists São Paulo's fragmented partisan scenario.

Key words: partisan bases; electoral geography; São Paulo

\section{RÉSUMÉ}

\section{Contexte et Compétition dans la Politique de l'État de São Paulo}

Dans cet article, on examine les transformations de la politique locale et des bases électorales des partis à São Paulo, dans l'après-1985. On a racheté les supposés de l'approche contextuelle et de la géographie électorale afin de montrer que la politique de l'État de São Paulo a des domaines spécifiques, et que aussi bien des facteurs structurels socio-économiques que le dynamisme des rapports entre le centre et la périphérie agissent dans le processus de formation des choix. Par rapport à la compétition dans cet État, on signale que, à partir de 1994, la politique à São Paulo suit la dynamique de la politique nationale, structurée dans la dispute bi-partidaire entre le PT et le PSDB. Enfin, sur l'organisation des bases des principaux partis, on signale que les partis organisés dès le début de cette période - PT, PSDB, PMDB, PDS/PP, PTB et $\mathrm{PFL} / \mathrm{DEM}$ - possèdent des bases avec un degré significatif d'enracinement dans l'électorat et qu'ils organisent leurs choix dans un mouvement qui résiste au panorama fragmenté des partis à São Paulo.

Mots-clés: bases des partis; géographie électorale; État de São Paulo 